\title{
Advances in synthesis of monocyclic $\beta$-lactams
}

\author{
Girija S. Singh and Siji Sudheesh \\ Chemistry Department, University of Botswana, Private Bag: 0022, Gaborone, Botswana \\ E-mail: singhgs@mopipi.ub.bw
}

DOI: http://dx.doi.org/10.3998/ark.5550190.0015.100

\begin{abstract}
Recent years have witnessed significant advancement in cycloaddition and cyclization strategies for the synthesis of monocyclic $\beta$-lactams. Cycloadditions include the Staudinger's ketene imine cycloaddtions and related reaction. Cyclization reactions are reported to furnish $\beta$-lactams through $\mathrm{N}_{1}-\mathrm{C}_{2}, \mathrm{~N}_{1}-\mathrm{C}_{4}$ and $\mathrm{C}_{3}-\mathrm{C}_{4}$ bond formations employing substrates like $\beta$-amino esters, $\beta$ amino alcohols, $\beta$-hydroxamate esters, and $\alpha$-amino diazocarbonyls, etc. Some other strategies are silyl carbonylation reactions, ring-enlargement of aziridines, cleavage of one ring of a bicyclic $\beta$-lactam, and functional group transformations on the $\beta$-lactam rings. Recently, some multi-component reactions have also been designed. This article reviews the advances made in synthetic approaches to monocyclic $\beta$-lactams during last five years.
\end{abstract}

Keywords: $\beta$-Lactams, cycloadditions, ketenes, nitrones, $\beta$-amino esters, aziridines

\section{Table of Contents}

1. Introduction

2. Synthetic Approaches to Construct $\beta$-Lactam Ring

2.1 Staudinger's Ketene-Imine Reactions

2.1.1 Applications of new ketene precursors

2.1.2 Applications of new azomethines

2.1.3 Applications of new acid activators

2.1.4 Some other stereoselective Staudinger reactions

2.1.5 Applications of $\alpha$-diazocarbonyls as ketene precursors

2.2 Ester-Enolate Cycloadditions

2.3 Alkyne-Nitrone Cycloadditions

2.4 Alkene-Isocyanate Cycloadditions

2.5 Torii's Cyclocarbonylation of Allyl halides with Imines 


\subsection{Expansion of Aziridine Rings}

2.7 Cyclization by Formation of $\mathrm{N}_{1}-\mathrm{C}_{2}$ Bond

2.8 Cyclization by Formation of $\mathrm{N}_{1}-\mathrm{C}_{4}$ Bond

2.9 Cyclization by Formation of $\mathrm{C}_{3}-\mathrm{C}_{4}$ Bond

2.10 Multi-Component Reactions

2.11 Other Approaches

3. Concluding Remarks

List of Abbreviations

References

\section{Introduction}

$\beta$-Lactams, the name still in vogue for four-membered cyclic amides 2-azetidinones, need no introduction to synthetic and medicinal organic chemists due to their widespread popularity as potential antibiotics and valuable building blocks in organic synthesis. $\beta$-Lactams constitute the most important class of antibiotics in both human and veterinary medicine and share more than $65 \%$ of the world antibiotics market. They are also in other clinical uses, like clavulanic acids as $\beta$-lactamase inhibitors and ezetimibe as cholesterol absorption inhibitor. Several other biological activities such as anticancer activity, hypoglycemic activity, antitubercular activity and antileishmanial activity have also been observed in compounds containing $\beta$-lactam ring. Over the years, monocyclic $\beta$-lactams have also emerged as powerful synthons and their reactivity has been exploited in synthesis of diverse type of acyclic and cyclic compounds including complex heterocyclic compounds of natural origin and of potential biological interest. Accordingly, the researches on synthesis, ${ }^{1}$ biological activity, ${ }^{2-5}$ and applications of $\beta$-lactams in organic synthesis, ${ }^{6-13}$, have been reviewed from time to time. ${ }^{1,14-19}$ This article aims to update the reports on synthesis of monocyclic $\beta$-lactams during last five years.

\section{Synthetic Approaches to Construct $\beta$-Lactam Ring}

The main synthetic approaches to construct the $\beta$-lactam ring involve either cycloaddition reactions or cyclization reactions. Cycloaddition reactions include the Staudinger's ketene-imine cycloaddtions, ester enolate-imine cycloadditions, alkyne-nitrone cycloadditions, alkeneisocyanate cycloadditions, and Torii's cyclocarbonylation of allyl halides with imines.

Cyclizations to monocyclic 2-azetidinones are reported recently through formation of $\mathrm{N}_{1}-\mathrm{C}_{2}$, $\mathrm{N}_{1}-\mathrm{C}_{4}$, and $\mathrm{C}_{3}-\mathrm{C}_{4}$ bonds. Methods involving $\mathrm{N}_{1}-\mathrm{C}_{2}$ bond formation employ $N$-protected or unprotected $\beta$-amino esters as substrate. Some other strategies involve cyclization of $\beta$-amino esters, $\beta$-amino alcohols suitably substituted amino diazocarbonyls. Different approaches have 
been applied to synthesize the $\beta$-amino esters. Hydroxamate esters cyclize by $\mathrm{N}_{1}-\mathrm{C}_{4}$ bond formation. $N, N$-Disubstituted $\alpha$-halo amides cyclize by $\mathrm{C}_{3}-\mathrm{C}_{4}$ bond formation.

Some other strategies for architecture of $\beta$-lactam ring employ ring-enlargement of aziridines or ring-contraction of isoxazolidines. Recently, some multi-component reactions have also been employed to achieve the goal.

\subsection{Staudinger's Ketene-Imine Reactions}

The Staudinger's ketene-imine cycloaddition is the most fundamental and versatile method for the synthesis of 2-azetidinones (Scheme 1). ${ }^{20}$ Although it is classified [2+2]-cycloaddition it involves a two-step process. The first step is the nucleophilic attack of the imine nitrogen to the electrophilic central carbon of a ketene, generated in situ from an acid chloride and a base, to form a zwitterionic intermediate followed by a conrotatory ring closure to give the fourmembered cycloadduct. Stereoselectivity is yet a challenging endeavor in this reaction. ${ }^{21}$ Tuba has recently reviewed transition metal-promoted Staudinger reactions. ${ }^{22}$ In recent years several new ketene precursors, new azomethine precursors, and acid activators have been developed. Both carboxylic acid chlorides or carboxylic acids themselves have been used as ketene precursors. An alternative method for generation of ketenes involves the Wolff-rearrangement of $\alpha$-carbonyl carbenes, generated from thermal or photochemical decomposition of $\alpha$ diazocarbonyls. ${ }^{23}$ The generation of ketenes using microwave irradiation and polymer-support are also reported. ${ }^{24,25}$ A detailed review of the literature on such reactions is described in the succeeding paragraphs.

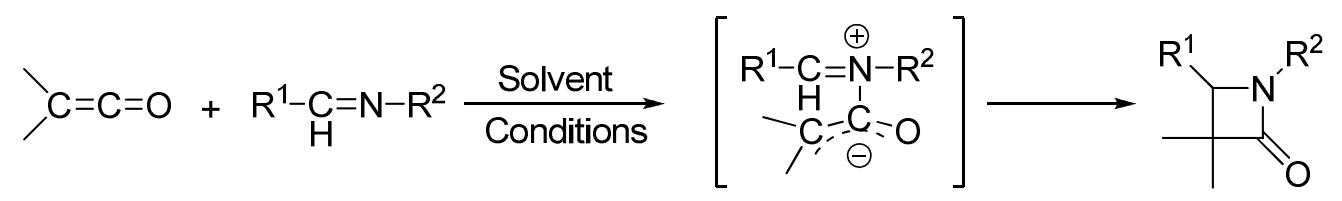

\section{Scheme 1}

2.1.1. Applications of new ketene precursors. The reaction of a chiral ketene, generated from the alkoxyacetic acid $\mathbf{1}$ bearing an $\alpha$-glycoside group as a chiral auxiliary, with $N$-chresenyl aldimine $\mathbf{2}$ in the presence of Mukaiyama's reagent $\mathbf{3}$ yielded a 45:55 mixture of the $\beta$-lactams 4 and 5 containing carbohydrate moiety in $70 \%$ combined yields. ${ }^{26}$ The separation of products by column chromatography and an acid-induced removal of the sugar moiety afforded the corresponding enantiopure products 6 and 7 (Scheme 2).

The [2+2] cycloaddition of hydrazones $\mathbf{8}$, prepared from aliphatic aldehydes and $(2 R, 5 R)-1$ amino-2,5-dimethylpyrrolidine, to $N$-benzyl- $N$-(benzyloxycarbonyl)aminoketene, generated in situ from the carboxylic acid 9, occurs in the presence of $i-\operatorname{Pr}_{2} \mathrm{EtN}$ base affording the corresponding 2-azetidinones 10 in good yields with $d r$ 's ranging from 54:46 upto 99:1 (Scheme 3). ${ }^{27}$ The reactions proceed with excellent stereocontrol to afford products having $R$ configuration at C-3 position. A strong influence of temperature was observed on the 
diastereoselectivity allowing in most cases the isolation of a single trans or cis cycloadducts simply by performing the reactions at $80{ }^{\circ} \mathrm{C}$ or room temperature, respectively.

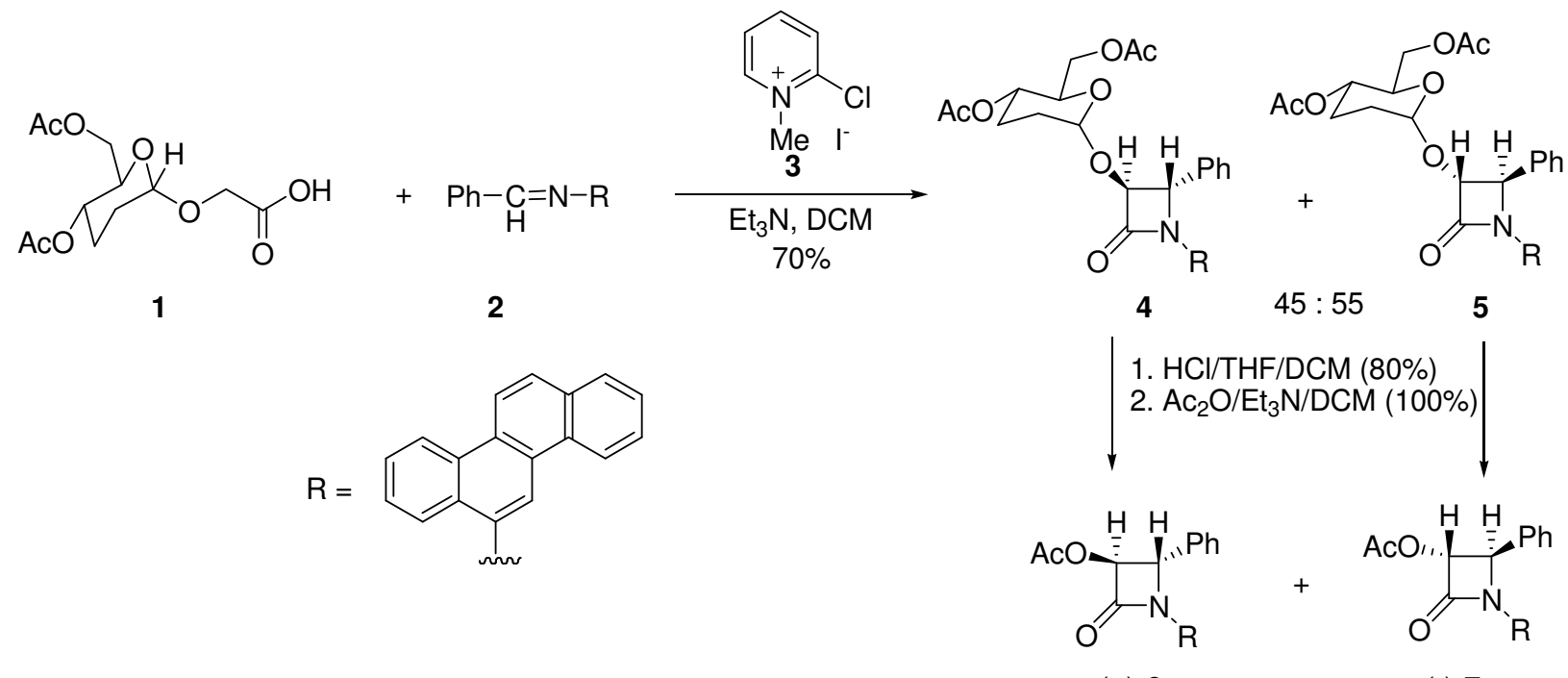

Scheme 2

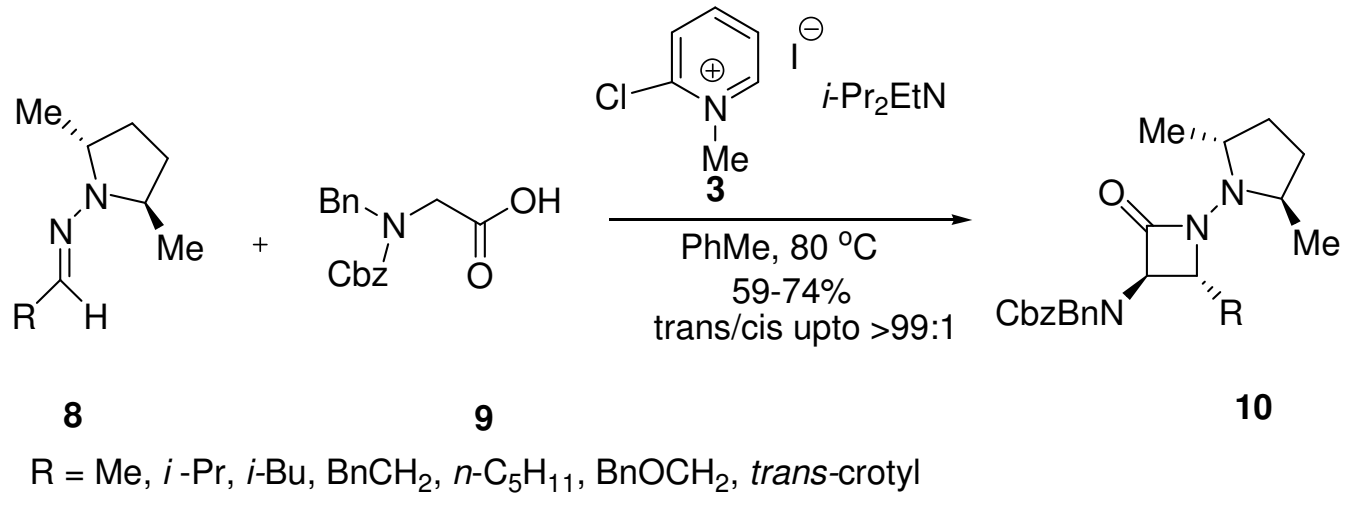

\section{Scheme 3}

Another example of a nitrogen-substituted ketene precursor is 2-(1H-pyrrol-1-yl)acetic acid 12. 2-(1H-Pyrrol-1-yl)ketene, generated from 2-(1H-pyrrol-1-yl)acetic acid $\mathbf{1 2}$ using Mukaiyama's reagent 3, reacts with some well-known aldimines $\mathbf{1 1}$ to afford the 3-pyrrol-1-yl-2azetidinones 13 (Scheme 4). ${ }^{28}$ 


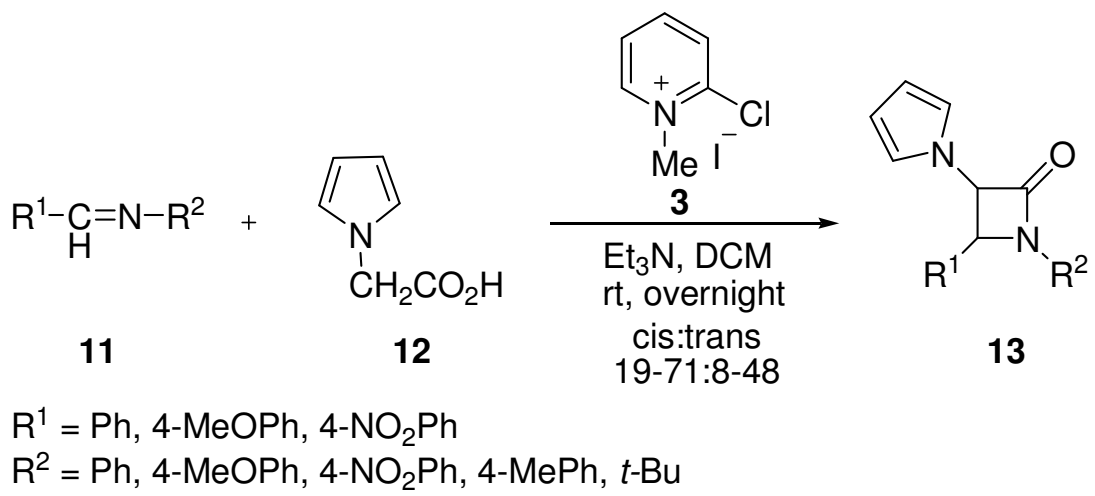

\section{Scheme 4}

The Staudinger reaction of mercaptoacetic acids 14 with Schiff bases 11 in the presence of the Vilsmeier reagent $\mathbf{1 5}$ at room temperature leading to the formation 3-thiolated 2azetidinones 16 in good to excellent yields constitutes an excellent example of application of a sulfur-substituted ketene precursor in the Staudinger reaction (Scheme 5). ${ }^{29}$ The reactivity of sulfur group on C-3 position has been further explored and selected 3-methylthio-2-azetidinones 16 have been transformed to the corresponding 3-(methylsulfonyl)- 17 and 3-(methylsulfinyl) 18 2 -azetidinones by treating with $m$-CPBA under different reaction conditions.
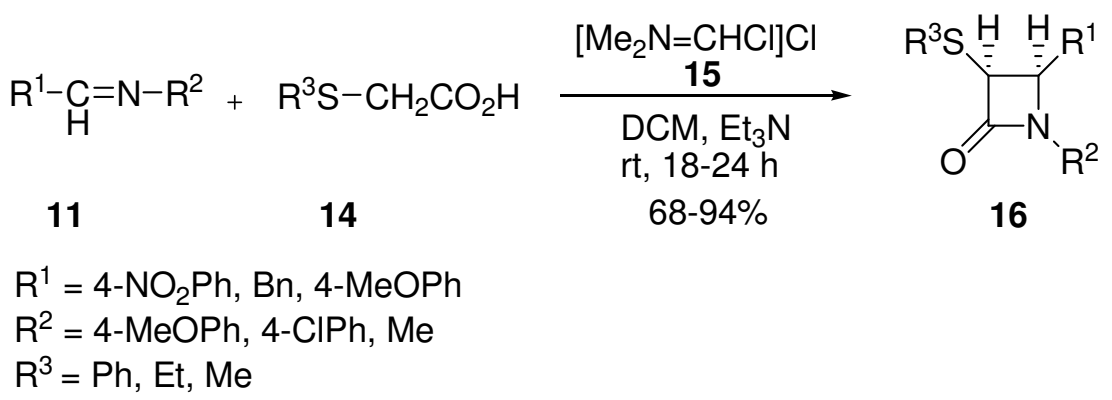

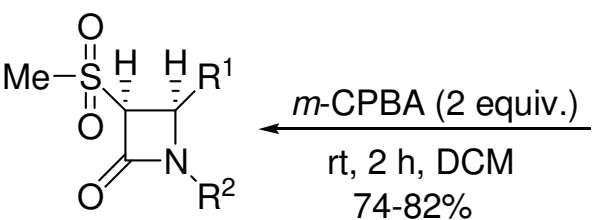

17

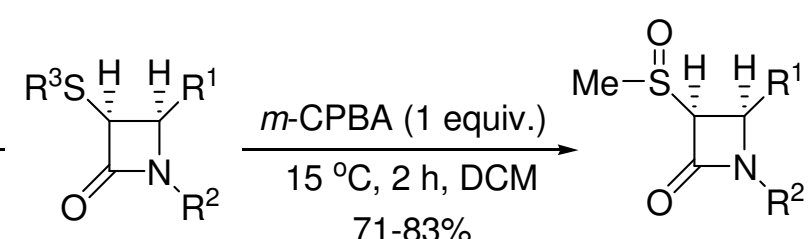

16
18

$\mathrm{R}^{1}=\mathrm{Bn}, 4-\mathrm{MeOPh}$

$\mathrm{R}^{2}=4-\mathrm{MeOPh}, 4-\mathrm{ClPh}, \mathrm{Me}$

$\mathrm{R}^{3}=\mathrm{Me}$

\section{Scheme 5}

Bari and coworkers have reported diastereoselective synthesis of novel seleniumsubstituted 2-azetidinones $\mathbf{2 0}$ by reaction of suitably substituted imines $\mathbf{1 1}$ and ketenes, generated 
from appropriate aryl- and alkylselenium-substituted acids 19 using $\mathrm{POCl}_{3}$ and triethylamine in refluxing toluene (Scheme 6) or benzene. ${ }^{30,31}$ The products obtained in good to excellent yields were having cis configuration of hydrogen atoms at C-3/C-4.

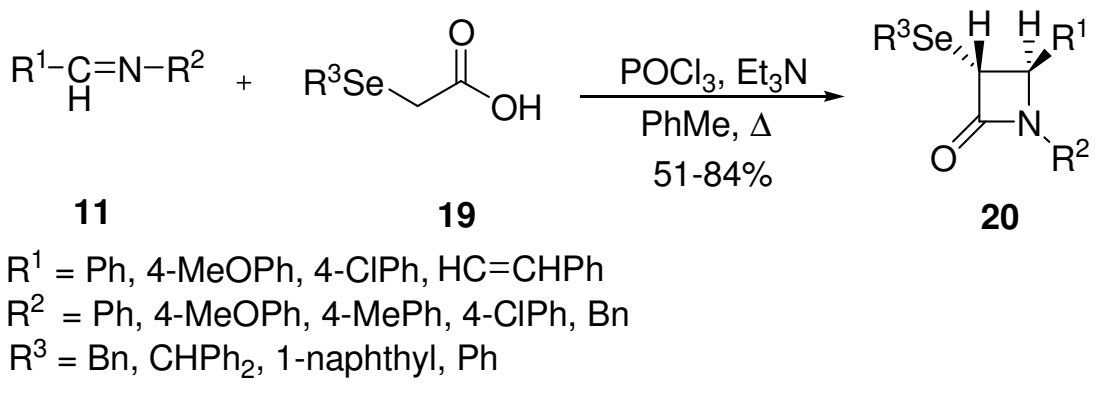

\section{Scheme 6}

2.1.2 Applications of new azomethines. More recently, the synthesis of a novel series of 2azetidinones 24 bearing an anthraquinone moiety at C-4 position has been reported using the imines 22 of 9,10-anthraquinone-2-carboxaldehyde 21 and ketenes, generated from aryloxy- and phthalimido-substituted acetic acids $\mathbf{2 3}$ in the presence of $p$-toluenesulfonyl chloride and triethylamine (Scheme 7). ${ }^{32}$<smiles>O=Cc1ccc2c(c1)C(=O)c1ccccc1C2=O</smiles>

21

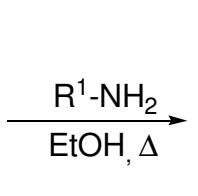<smiles>[R]N=Cc1ccc2c(c1)C(=O)c1ccccc1C2=O</smiles>

22

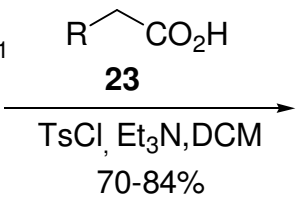

$70-84 \%$<smiles>[R]C1C(=O)N([R])C1c1ccc2c(c1)C(=O)c1ccccc1C2=O</smiles>

24

$\mathrm{R}^{1}=1$-naphthyl, 4-MeOPh, 4-Me ${ }_{2} \mathrm{NPh}$

$\mathrm{R}=\mathrm{PhO}, 4-\mathrm{ClPhO}$, 1-naphthoxy, PhthN, 2,4- $\mathrm{Cl}_{2} \mathrm{PhO}$

\section{Scheme 7}

The reaction of vicinal diimines $\mathbf{2 5}$ and acyl chlorides in the presence of triethylamine furnishes 3-imino- $\beta$-lactams 26 and/or bis- $\beta$-lactams chemo-, regio-, and stereoselectively. ${ }^{33}$ The selectivities in the reaction have been investigated using different substrates such as symmetric diimines derived from vicinal diketones, and unsymmetrical diimines from vicinal ketoaldehydes. The study revealed that all diimines reacted with various ketenes providing mono-cis- 2-azetidinones $\mathbf{2 6}$ diastereoselectively due to the electron-withdrawing property of another imino group in the vicinal diimines (Scheme 8). Bis-2-azetidinones were obtained from diimines via mono-2-azetidinones. Usually the formation of first $\beta$-lactam ring inhibited the formation of the second ring. But the ketene with strong electron-donating substituent such as 
ethoxyketene reacted with the mono-cis-2-azetidinones containing azomethine linkage to provide the bis-2-azetidinones.<smiles>[R7]N=C(C)C([R])=N[3H]</smiles>

25<smiles>[R]CC(=O)Cl</smiles>

$42-87 \%$

$$
\begin{aligned}
& \mathrm{R}^{1}=4-\mathrm{MeOPh}, \mathrm{Ph}_{2} \mathrm{CH}, \mathrm{Ph}, \mathrm{Bn} \\
& \mathrm{R}^{2}=\mathrm{Me}, \mathrm{H} \\
& \mathrm{R}=\mathrm{EtO}, \mathrm{PhthN}, \mathrm{Cl}, \mathrm{Me}
\end{aligned}
$$



\section{Scheme 8}

Tato and coworkers have reported the Staudinger reaction of $N$-nosyl imines 27 and dichloroketene, generated in situ from dichloroacetyl chloride 28, to furnish the 1-nosyl-3,3dichloro-2-azetidinones 29 in good yields (Scheme 9). ${ }^{34}$ These 2-azetidinones undergo ringopening to afford highly functionalized building block. The reaction of chloroacetyl chloride with some bis-imines in the presence of zeolite is reported by microwave irradiation forming bis2-azetidinones. ${ }^{35}$

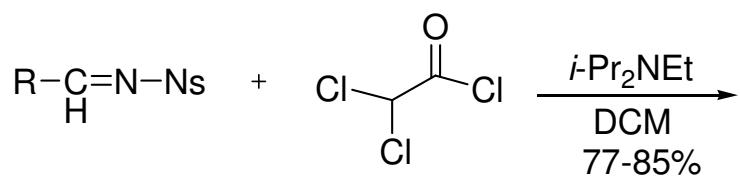

27<smiles>[R]C1N([S+](=O)[O-])C(=O)C1(Cl)Cl</smiles>

29

$\mathrm{R}=\mathrm{Ph}, 2$-naphthyl, 4-i-PrPh, 3-CNPh, 2-FPh

$\mathrm{Ns}=\mathrm{SO}_{2}-4-\mathrm{NO}_{2} \mathrm{C}_{6} \mathrm{H}_{4}$

\section{Scheme 9}

Azomethines 32 are generated in situ by copper-catalyzed reaction of the Grignard reagents with $N$-substituted methyleneaziridines $\mathbf{3 0}$ inducing aziridine ring opening and alkylation of the resulting metalloenamine 31 (Scheme 10). ${ }^{36}$ These azomethines reacted with alkoxyketenes, generated from acyl chlorides $\mathbf{3 3}$ and $\mathrm{Et}_{3} \mathrm{~N}$, to yield C-3 alkoxy-substituted 2-azetidinones $\mathbf{3 4}$. 


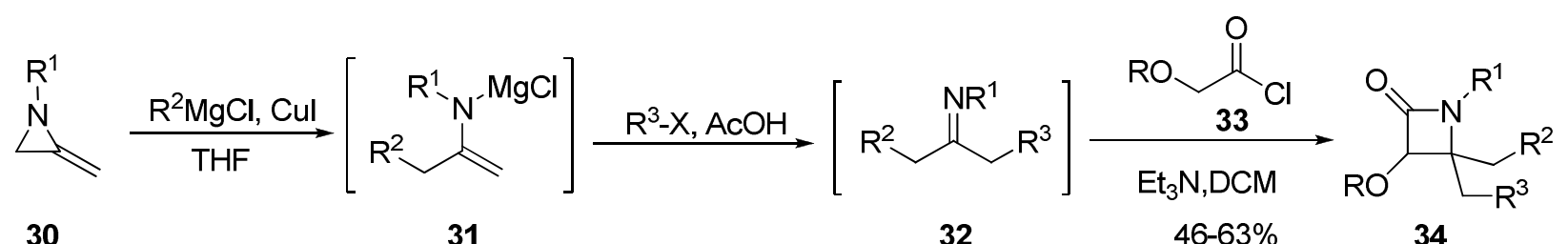

$\mathrm{R}^{1}=4-\mathrm{MeOBn}, \mathrm{Bn}, \mathrm{C}-\mathrm{Hex}$

32

34

$\mathrm{R}^{2}=\mathrm{Bn}, \mathrm{Et}, i-\mathrm{Pr}$

$\mathrm{R}^{3}-\mathrm{X}=\mathrm{BnBr}, \mathrm{BnCl}, \mathrm{CH}_{2}=\mathrm{CHCH}_{2} \mathrm{Br}, \mathrm{PMBCl}$, Mel, THPO $\left(\mathrm{CH}_{2}\right)_{3} \mathrm{Br}, \mathrm{H}_{3} \mathrm{CC} \equiv \mathrm{CCH}_{2} \mathrm{Br}$

$\mathrm{R}=\mathrm{Bn}, \mathrm{Me}$

\section{Scheme 10}

$(S)$-2-Chloropropan-1-ol 35 has been used as azomethine precursor in an efficient one-pot approach towards chiral 2-azetidinones 37 in reasonable yields $(32-61 \%, 19-43 \%$ after purification) and high diastereomeric (80-89\%) and enantiomeric excess $(90 \%) .{ }^{37}$ An oxidation of alcohol 35 with pyridinium cholorochromate (PCC) afforded the corresponding aldehyde which on treatment with 1 equivalent of amines yielded the $(S)-N$-(2-chloropropylidene)amines 36. The reaction of azomethines $\mathbf{3 6}$ with benzyloxy- or methoxyacetyl chloride $\mathbf{3 3}$ under Staudinger conditions gave the corresponding 2-azetidinones (Scheme 11). The reaction of methoxyketene with imine containing $N$-butyl group, however, afforded an extremely low yield of $6 \%$ due to unexplained reasons.

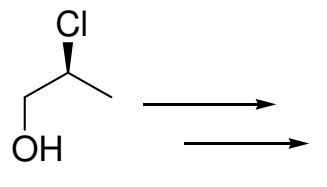

35<smiles>N=CC(Cl)Cl</smiles>

36<smiles>O=C(Cl)CO</smiles>

33

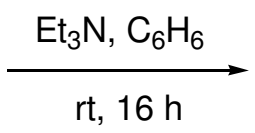

$6-43 \%$

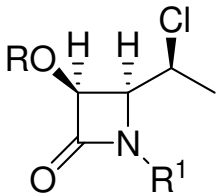

37

$\mathrm{R}^{1}=\mathrm{Bn}$, allyl, $\mathrm{Bu}, i-\mathrm{Bu}, i-\mathrm{Pr}$

$\mathrm{R}=\mathrm{Bn}, \mathrm{Me}$

\section{Scheme 11}

The use of $\mathrm{N}$-phenylsulfenylimines $\mathbf{3 8}$ in the Staudinger reaction with methoxy- or benzyloxyacetyl chlorides 33 afforded 3,4-disubstituted $N$-phenylsulfenyl-2-azetidinones 39 in good to excellent yields and with moderate cis/trans diastereoselectivity (Scheme 12). ${ }^{38}$ The choice of diisopropylethylamine as a non-nucleophilic Lewis base was essential for the success of reaction. The cis-diastereomers were the major products with benzyloxy and methoxyketene and this diastereoselectivity increased with the electron-withdrawing ability of the substituent on imine. However, the trans-diastereomer was the major product with imines derived from electron-rich aldehydes. 


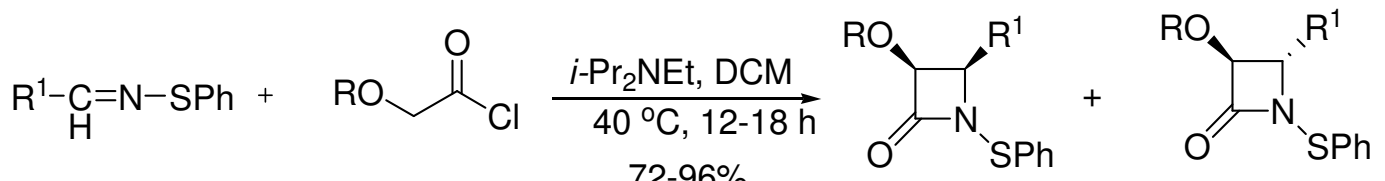
38 33

39

$\mathrm{R}^{1}=i-\mathrm{Pr}, t-\mathrm{Bu}, \mathrm{Ph}, 4-\mathrm{Me}_{2} \mathrm{NPh}, 4-\mathrm{MeOPh}$, 4-MeSPh, 4-FPh, 2-FPh, 3-FPh, 4-CF 3 Ph, 4- $\mathrm{MeCO}_{2} \mathrm{Ph}, 4-\mathrm{CNPh}, 4-\mathrm{NO}_{2} \mathrm{Ph}, 2$-pyridyl, 2-furyl, 2-thienyl

$\mathrm{R}=\mathrm{Me}, \mathrm{Bn}$

\section{Scheme 12}

A one-pot cascade approach to 4-alkylidine-2-azetidinones $\mathbf{4 3}$ from aryl azides $\mathbf{4 0}$ and aryloxyacetyl chlorides $\mathbf{3 3}$ has been reported. ${ }^{39}$ The cascade process involves an aza-Wittig reaction of ketenes, generated in situ from acid chlorides 33, with triphenylphosphazenes 41 forming ketenimines 42, which in turn, react with ketenes by a [2+2]-cycloaddition. The electron-rich aryl azides offered better yields than the electron-deficient aryl azides (Scheme 13).

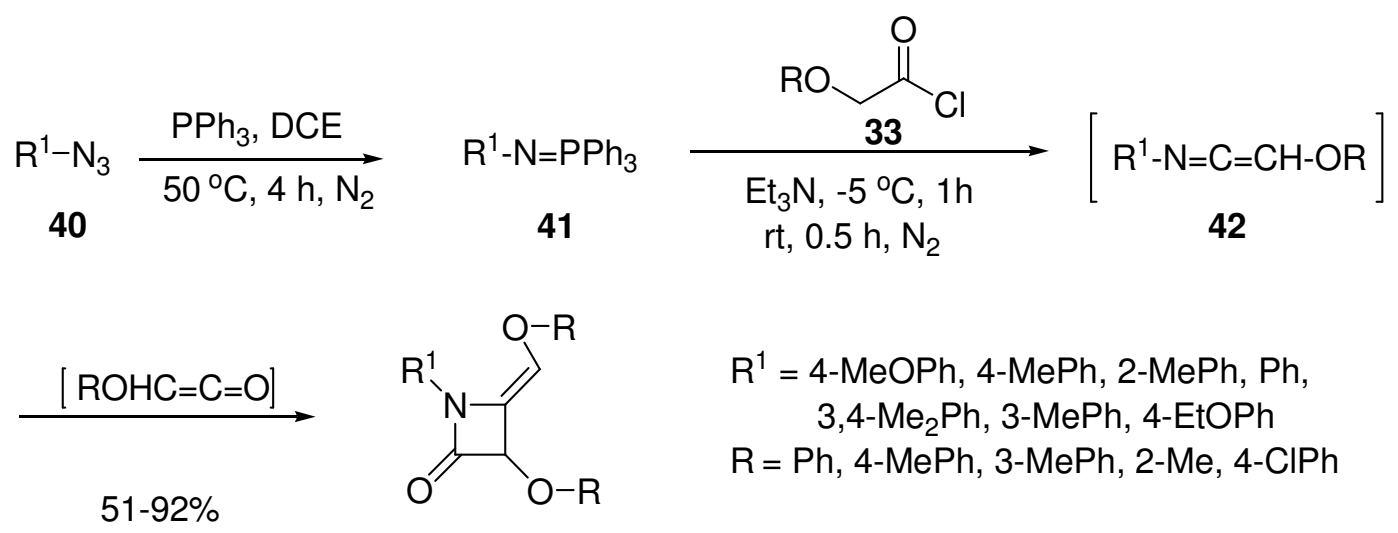

43

\section{Scheme 13}

A highly diastereoselective one-pot synthesis of trifluoromethylated trans- 2-azetidinones $\mathbf{4 5}$ using $\mathrm{N}$-tosyl-1-chloro-2,2,2-trifluoroethylamine $4 \mathbf{4}$ and various nonactivated aliphatic acid chlorides in the presence of DMEA is reported (Scheme 14). ${ }^{40}$ The reaction provided the 2azetidinones in good yields with excellent diastereoselectivity upto 99:1. An improved yield was, however, obtained from 3-phenylpropanoyl chloride. Although the diastereomeric ratio was high with $\mathrm{R}=\mathrm{Me}$ and Et the diastereoselectivity was total with bulkier $\mathrm{R}$ groups ( $\mathrm{Pr}, i-\mathrm{Pr}, \mathrm{Bu}, t$ - $\mathrm{Bu}$, $\left.\mathrm{CH}_{2} \mathrm{Ph}\right)$. 

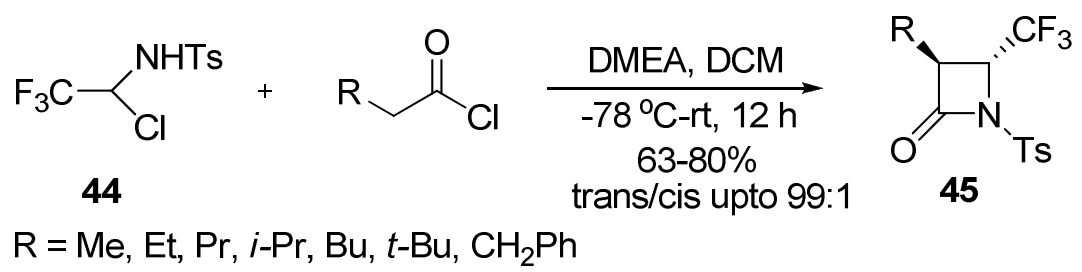

45

\section{Scheme 14}

Deshmukh and coworkers have employed isosorbide, a by-product from starch industry, to synthesize chiral bicyclic aldehydes 46 . Imines 47 of this aldehyde react with alkoxy-, acetoxy-, phenoxy-, and benzyloxyketenes, obtained from the respective acyl chlorides $\mathbf{3 3}$, to afford the cis-2-azetidinones 48, as a single diastereoisomer (Scheme 15). ${ }^{41}$ The application of isosorbidederived chiral acetic acid derivatives as ketene precursors, however, resulted in moderate to low diastereoselectivity.

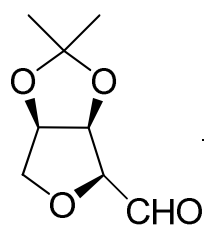

46<smiles>[R1]N=CC1OCC2OC(C)(C)O[C@H]12</smiles>

47<smiles>[R]OC(=O)C(=O)N(CC)OCC</smiles>
$60-78 \%$

$\mathrm{R}^{1}=4-\mathrm{MeOPh}, \mathrm{Bn}, 4-\mathrm{CIPh}$

$\mathrm{R}=\mathrm{OMe}, \mathrm{OBn}, \mathrm{OPh}, \mathrm{OAc}$,

\section{Scheme 15}

2.1.3 Development of new acid activators. Several reports in recent years especially from Zarei and coworkers focused on the efficient use of new acid activators, such as diethyl chlorophosphate $\mathbf{4 9},{ }^{42}$ cyanuric chloride-DMF complex $\mathbf{5 0},{ }^{43}$ thiocarbonyldiimidazole $\mathbf{5 1},{ }^{44}$ and DMF-dimethyl/diethylsulfate 52, ${ }^{45}$ in Staudinger reactions. The reactions of various imines 11 and substituted acetic acids $\mathbf{2 3}$ in the presence of these reagents at room temperature afford 2azetidinones 53 in excellent yields (Scheme 16). More recently Zarei group has reported cyanuric fluoride, ${ }^{46}$ and phosphonitrilic chloride, ${ }^{47}$ as efficient acid activators. 




11



23
$49 / 50 / 51 / 52$

$\mathrm{DCM}, \mathrm{Et}_{3} \mathrm{~N}, \mathrm{rt}, 12 \mathrm{~h}$

49- $76-88 \% ; 50-39-86 \%$ 51- 83-94\%; 52- 26-82\%

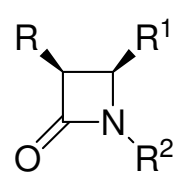

53

$\mathrm{R}^{1}=4-\left(\mathrm{Me}_{2} \mathrm{CHPh}\right)$, 4-NO ${ }_{2} \mathrm{Ph}, 4-\mathrm{CIPh}, 4-\mathrm{MePh}, 4-\mathrm{MeOPh}, \mathrm{Ph}-\mathrm{CH}=\mathrm{CH}$

$\mathrm{R}^{2}=4-\mathrm{EtOPh}, \mathrm{Bn}, 4-\mathrm{MeOBn}, 4-\mathrm{MeOPh}$

$\mathrm{R}=\mathrm{PhO}, 2,4-\mathrm{Cl}_{2} \mathrm{PhO}, 2$-naphthyl, PhthN, 4-CIPhO, $\mathrm{MeO}$<smiles>CCOP(=O)(Cl)OCC</smiles>

49<smiles>C[N+](C)=COc1nc(C(C)(C)C)nc(C(C)(C)C)n1</smiles>

50<smiles>S=C(c1ncc[nH]1)c1ncc[nH]1</smiles>

51<smiles>C[N+](C)=C(O)O[Sb]</smiles>
$\mathrm{R}=\mathrm{Me}, \mathrm{Et}$

52

\section{Scheme 16}

2.1.4 Some other stereoselective Staudinger reactions. A highly stereoselective synthesis of 3(1H-pyrrol-2-yl)-substituted 2-azetidinones $\mathbf{5 8}$ and $\mathbf{5 9}$ is reported through the Staudinger reaction of imines 11 with phthalimido acetic acid 53 affording the 2-azetidinones 54 and 55 (Scheme 17). ${ }^{48}$ Treatment of the latter compounds with ethylenediamine afforded 3 -amino-2-azetidinones 56 and 57 which reacted with 2,5-dimethoxytetrahydrofuran in the presence of bismuth nitrate to afford the 3-pyrrole-substituted 2-azetidinones $\mathbf{5 8}$ and 59, respectively. The reaction was relatively much faster under microwave irradiation. The polyaromatic imines derived from 6chrysenyl amine produced (+)-trans isomer exclusively. The electron-withdrawing aromatic groups at the $\mathrm{C}$ - and $\mathrm{N}$ - terminus of the imine led to the formation of the trans isomer. The formation of trans isomer in the case of $\mathrm{N}$-chrysenyl imines and diarylimines was rationalized through isomerization of the enolate as described by Banik and coworkers. ${ }^{49}$ A polyaromatic group at the nitrogen stabilizes the iminium ion, but in the case of a monocyclic aromatic group, the electron-withdrawal properties are not sufficient to have complete isomerization of the enolate resulting into formation of a mixture of trans and cis isomers. 


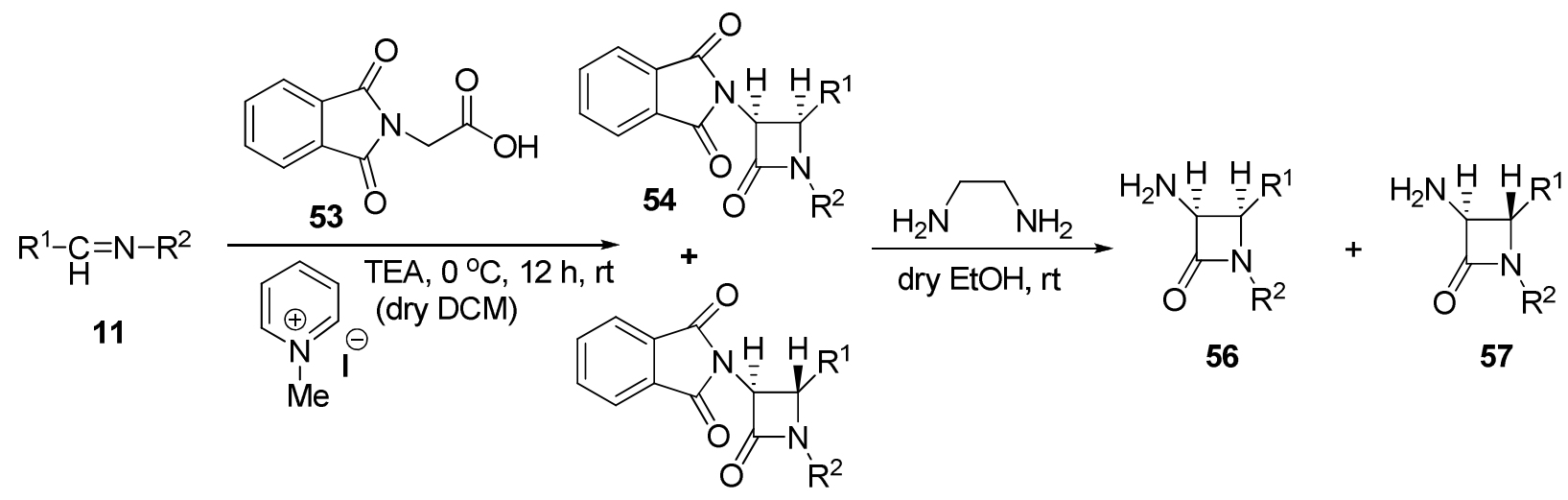

55

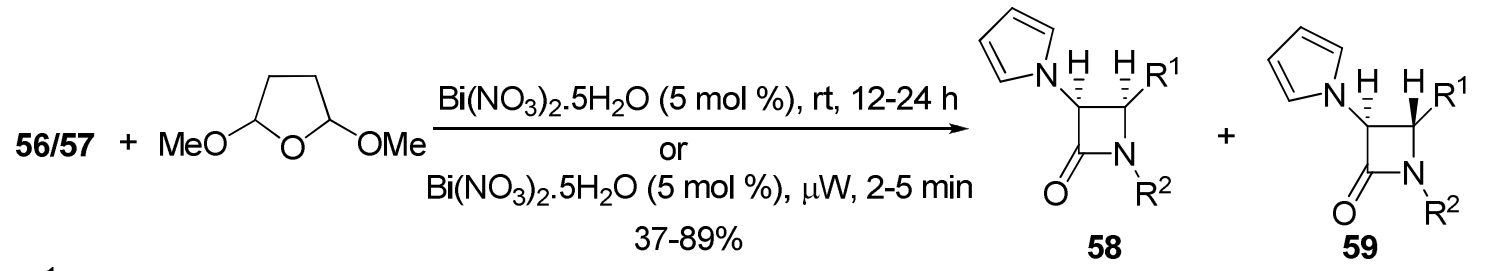

$\mathrm{R}^{1}=\mathrm{Ph}, 4-\mathrm{MeOPh}, 2$-thienyl, 2-pyridyl, ferrocenyl

$\mathrm{R}^{2}=\mathrm{Ph}, 4-\mathrm{MeOPh}, 6$-chrysenyl

\section{Scheme 17}

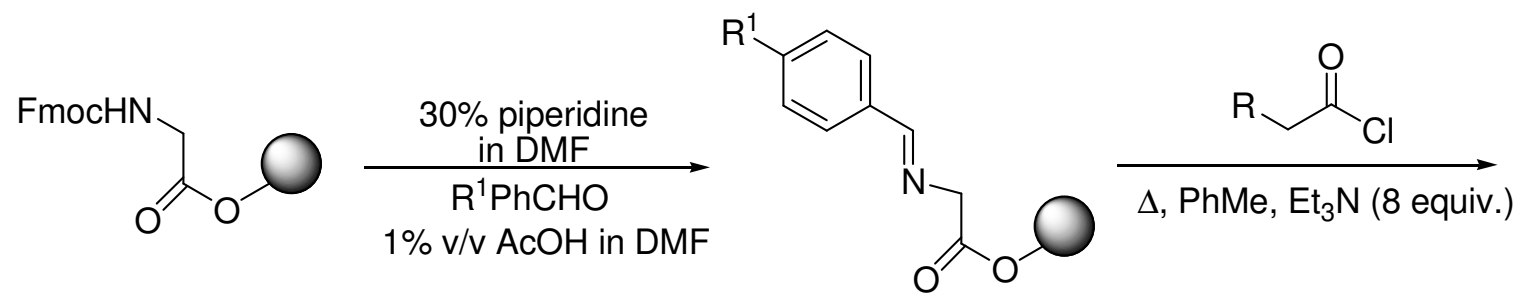

60

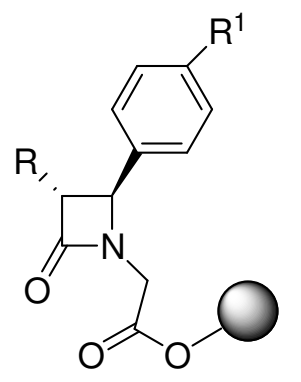

62
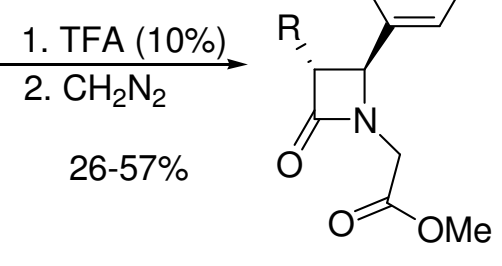

63

\section{Scheme 18}

A solid-phase strategy has been employed for the rapid generation of two small libraries of trans 3-alkyl-substituted 2-azetidinones. ${ }^{50}$ The synthetic sequence of the glycine-derived library originates from the Wang resin-tethered Fmoc-glycine 60. Addition of a controlled excess of alkanoyl chlorides (4 equiv.) and triethylamine (8 equiv.) to the resin bound imines $\mathbf{6 1}$ in 
refluxing toluene led to the formation of 2-azetidinones 62. Cleavage from the resin surface using trifluoroacetic acid and treatment with diazomethane afforded the 3-alkyl 2-azetidinones 63 as a single product with excellent trans selectivity (Scheme 18). In the second library, Fmocprotected $p$-aminophenol 64 was attached to the Wang resin. The resin bound imine 66, obtained from the reaction of resin-bound aminophenol 65 and $p$-anisaldehyde, was then reacted with 5phenylpentanoic acid in the presence of triethylamine using the Mukaiyama's reagent 3. The detachment of resin from the 2-azetidinone 67 by trifluoroacetic acid afforded the 2azetidinone $\mathbf{6 8}$ (Scheme 19).

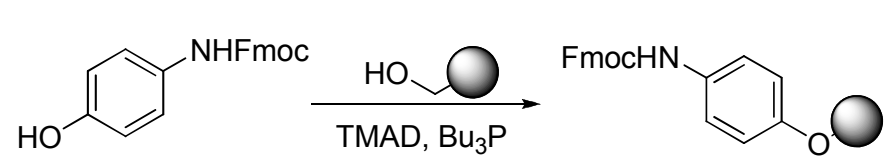

64
65

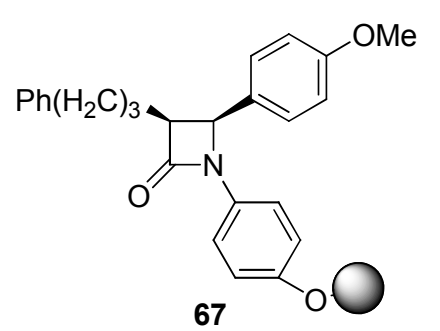



in DMF

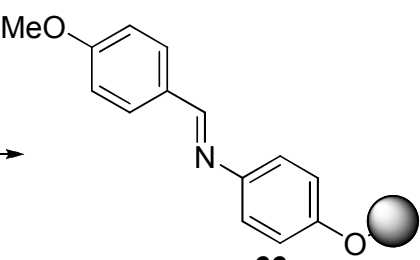

66

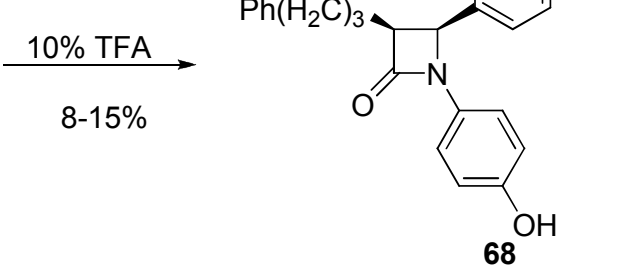

\section{Scheme 19}

The Pd-catalyzed tandem carbonylation-Staudinger cycloaddition gives 2-azetidinones $\mathbf{7 0}$ in good yields with excellent trans diastereoselectivity except in cases where an $N$-benzylsubstituted imine or the $N$-tosylhydrazone salt containing a strong electron-donating substituent was used. ${ }^{51}$ When $N$-tosylhydrazone salts 69 are heated in the presence of a palladium catalyst under pressure of $\mathrm{CO}$, ketene intermediates are generated in situ that undergo reaction with imines 11 to afford the 2-azetidinones $\mathbf{7 0}$ (Scheme 20).

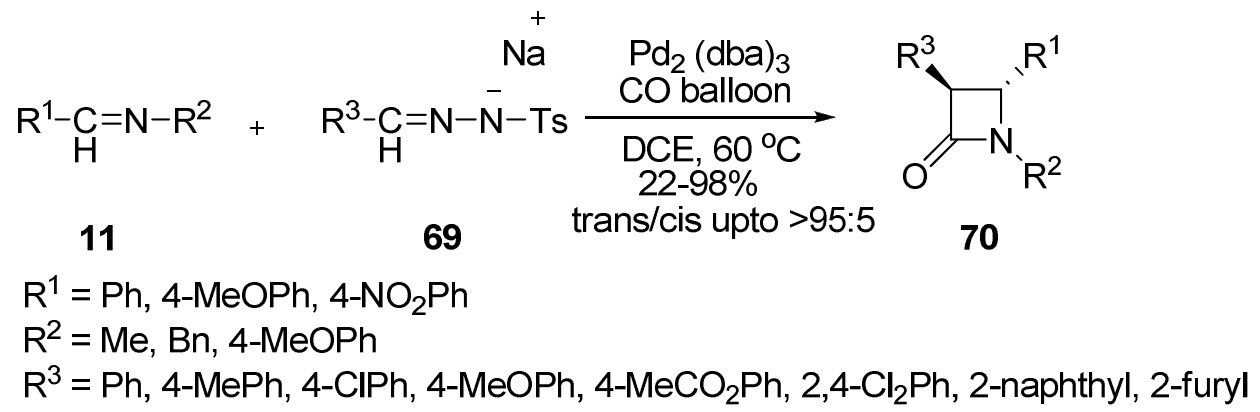

\section{Scheme 20}


An asymmetric synthesis of 2-azetidinones through the ketene-imine [2+2]-cycloaddition has been achieved employing $N$-heterocyclic carbenes (NHCs) as efficient catalysts. ${ }^{52,53}$ The imidazolinium catalyst $\mathbf{7 3}$ or triazolium catalyst $\mathbf{7 4}$ has been used in the reaction of diphenylketene $\mathbf{7 1}$ with $\mathrm{N}$-tosylaldimines $\mathbf{7 2}$ to give the corresponding 2-azetidinones $\mathbf{7 5}$ in excellent yields (Scheme 21). ${ }^{54}$ Another chiral NHC 77, derived from L-pyroglutamic acid, catalyzed the reactions of arylalkylketenes 71 with a variety of $N$-tert-butoxycarbonyl arylimines $\mathbf{7 6}$ to give the corresponding cis-2-azetidinones $\mathbf{7 8}$ in good yields with good diastereoselectivities and excellent enantioselectivity (upto $99 \%$ ee) (Scheme 22). ${ }^{55}$

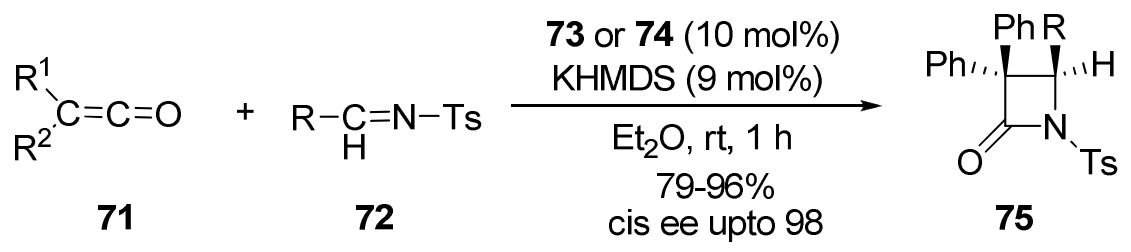

$\mathrm{R}=\mathrm{Ph}$; 2-naphthyl; 2-furyl; 4-BrPh

$\mathrm{R}^{1}=\mathrm{R}^{2}=\mathrm{Ph}$

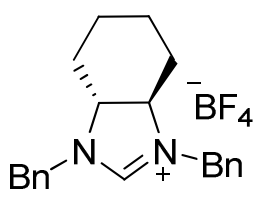

73

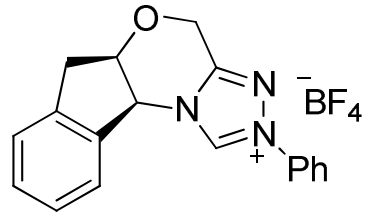

74

\section{Scheme 21}

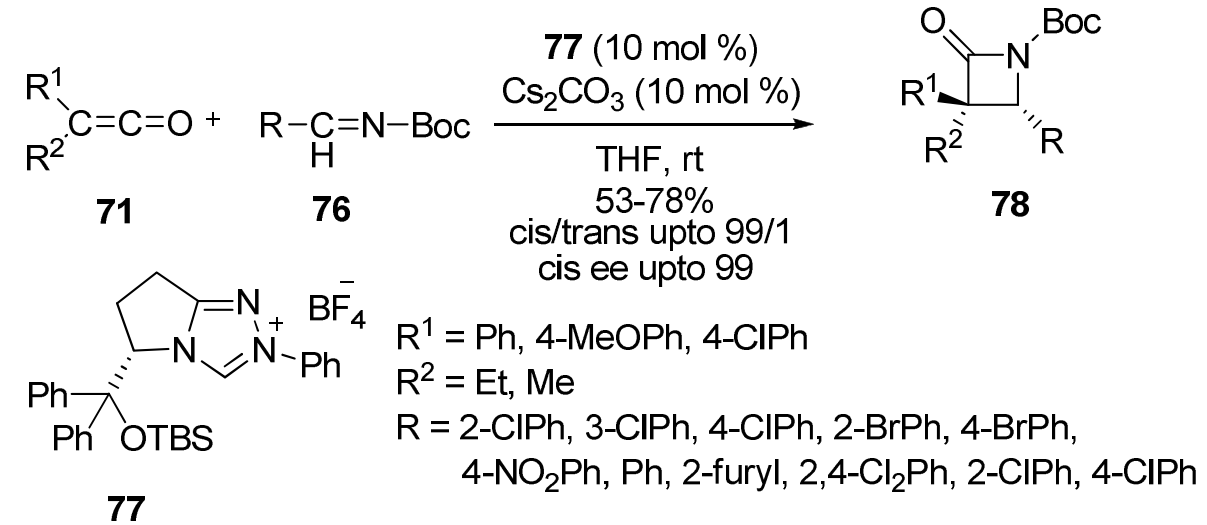

\section{Scheme 22}

A highly diastereoselective synthesis of trans-2-azetidinones $\mathbf{8 2}$ by a [2+2] cycloaddition between silyl ketene acetals 79 and imines 80 using a phosphonium fluoride multifunctional catalyst 81 (Scheme 23) has been reported. ${ }^{56}$ The phosphonium fluoride precatalyst activates the nucleophile and also directs the reaction process for high yield and diastereoselectivity. The precatalyst acts to initiate the reaction because of the high affinity of the fluoride ion for the 
TMS group of the silyl ketene acetal 79. The bulk of the phosphonium cation was also essential to organize a transition state in such a way that the trans-diastereomer is kinetically favored.

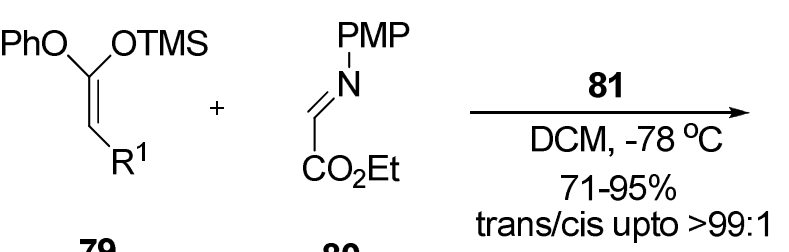

80<smiles>[R]C(C(=O)OCC)=C(N=[PH2])C(=O)OCC</smiles>

<smiles>[R1]C1C(=O)N([R16])[C@H]1C(=O)OCC</smiles>

82

$\mathrm{R}^{1}=\mathrm{Me}, \mathrm{Et}, i-\mathrm{Pr},\left(\mathrm{CH}_{2}\right)_{2} \mathrm{Cl}, \mathrm{CH}_{2} \mathrm{SMe}, \mathrm{Bn}, \mathrm{PhO}$ $\mathrm{R}=4-\mathrm{MePh}$

81

\section{Scheme 23}

De Kimpe and coworkers have reported the synthesis of trans-4-aryl-3-(3chloropropyl)azetidin-2-ones $\mathbf{8 4}$ in good yields by the Staudinger reaction between imines 11 and 5-chloropentanoyl chloride $\mathbf{8 3}$ in the presence of 2,6-lutidine (Scheme 24). ${ }^{57}$ The product azetidin-2-ones serve as precursor for 2-arylpiperidine-3-carboxylates.

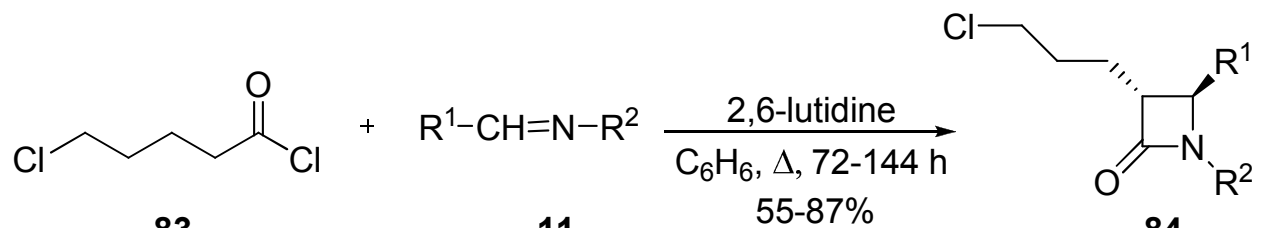

83

11

$55-87 \%$

84

$\mathrm{R}^{1}=i-\mathrm{Pr}$, Et, Bn, 4-MeOBn, C-Hex

$\mathrm{R}^{2}=\mathrm{Ph}, 4-\mathrm{MePh}, 4-\mathrm{MeOPh}$

\section{Scheme 24}

Singh and coworkers have reported the reaction of trans-cinnamaldehyde imines $\mathbf{8 5}$ with azido-ketene, generated in situ from 2-azidoethanoic acid $\mathbf{8 6}$ in the presence of $p$-toluenesulfonyl chloride and triethylamine in dry dichloromethane, to afford the cis-3-azido-2-azetidinones 87 (Scheme 25). ${ }^{58}$ The reductive cleavage of azide group in the latter compounds afforded 3 -amino2 -azetidinones 88. A [2+3]-cycloaddition of the azide group with various alkynes led to the synthesis of triazole-tethered 2-azetidinones. Both azide and amino functionalities are of immense significance in organic synthesis and can be further transformed to diverse types of compounds containing $\beta$-lactam ring. 
<smiles>[R]N=C/C=C/c1ccccc1</smiles>

85

86

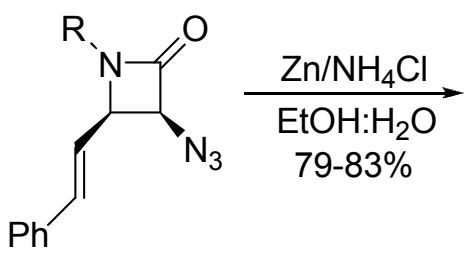

87<smiles>[R]N1C(=O)[C@@H](N)[C@H]1/C=C/c1ccccc1</smiles>

88

$\mathrm{R}=\mathrm{Ph}, 4-\mathrm{MePh}, 4-\mathrm{ClPh}, \mathrm{C}$-hex, Bn

\section{Scheme 25}

2.1.5 Application of $\alpha$-diazocarbonyls as ketene precursors. $\alpha$-Diazocarbonyls are wellknown to furnish ketenes under thermal and photochemical conditions. ${ }^{23}$ The photochemical reaction of 2-diazo-1,2-diphenylethanone with some imines to yield 2-azetidinones was reported by our group in 1980s. ${ }^{59}$ Recently, 3-alkoxy/aryloxy- 2-azetidinones 90 and 91 have been synthesized in satisfactory to good yields by a photo-induced Staudinger reaction of imines 11 and alkyl/aryl diazoacetates 8 89. $^{60}$ The alkoxy/aryloxyketenes, generated, in situ from photochemical decomposition of diazoacetates $\mathbf{8 9}$ and the Wolff rearrangement of the resulting carbenes, ${ }^{61}$ underwent the Staudinger reaction with various imines $\mathbf{1 1}$ to give the 2-azetidinones 90 and 91 (Scheme 26). The trans-2-azetidinones were the major products from linear imines that is attributed to the isomerization of the imines from their trans isomers into cis-isomers under UV irradiation.<smiles>[R9]C(=O)C=[W]</smiles>

89<smiles>[R]C=N[CH]</smiles>

11



cis/trans upto $67: 33$

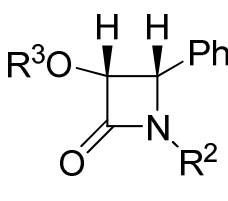

90<smiles>[R9]O[C@H]1C(=O)N([R])[C@H]1[C@H]([2H])c1ccccc1</smiles>

91 $\mathrm{R}^{1}=\mathrm{Ph} ; \mathrm{R}^{2}=\mathrm{Ph}, \mathrm{Bn} ; \mathrm{R}^{3}=i-\mathrm{Pr}, \mathrm{Bn}, \mathrm{Ph}$

\section{Scheme 26}

Our group has reported recently the thermal decomposition of 2-diazo-1,2-diarylethanones 92 in the presence of $N$-substituted imines of 1-methylindole-3-carboxaldehydes 93 affording 3,3-diaryl-4-(1-methylindol-3-yl)-2-azetidinones 94 in good yields (Scheme 27). ${ }^{62}$ These 2azetidinones exhibited excellent antileishmanial activity besides some antibacterial, antifungal, and crown gall-tumor activity. ${ }^{63}$ Previously, similar reactions of $N$-salicylideneamines were reported to afford the 2-azetidinones with significant antibacterial and antifungal activity. ${ }^{64}$ 


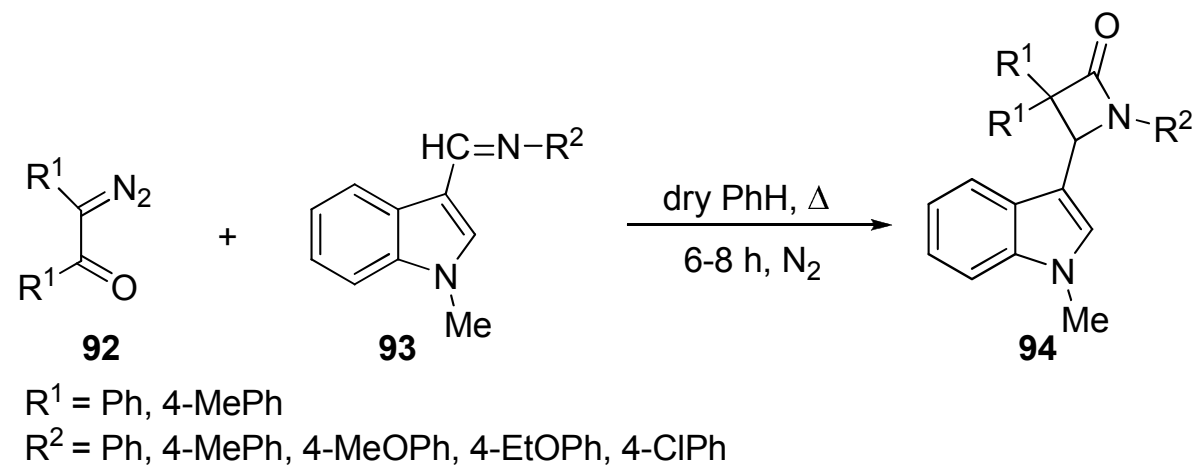

\section{Scheme 27}

\subsection{Ester-Enolate Cycloadditions}

The ester enolate - imine cyclocondensation provides 2-azetidinones in good yields with higher stereoselectivity. Some recent reactions have been mediated by zinc, ${ }^{65}$ rhodium,${ }^{66}$ indium, ${ }^{67}$ and diethylzinc. ${ }^{68}$ Boyer and coworkers have studied the parameters influencing the selective synthesis of 2-azetidinones 96 or $\beta$-amino esters 97 during the Reformatsky reaction of ethyl bromodifluoroacetate 95 with imines 1 11. $^{65}$ The ratio between $\beta$-amino ester and $\beta$-lactam depends on the nature of the imine and the reactions conditions. The diastereoselectivity of the reaction was highly dependent on the nature of the chiral auxiliary. Moreover gem-difluoro-2azetidinones 96 and $\mathrm{gem}$-difluoro- $\beta$-amino esters 97 were obtained with high stereoselectivity by using either $(R)$-phenylglycinol or $(R)$-methoxyphenylglycinol (Scheme 28$)$. The diethylzincmediated Reformatsky-type reaction of ethyl dibromofluoroacetate $\mathbf{9 8}$ with imines $\mathbf{1 1}$ led to the diastereoselective synthesis of $c i s$ - $\alpha$-bromo- $\alpha$-fluoro-2-azetidinones 99 in good yields (Scheme 29). ${ }^{68}$ In this reaction, the imine from the reaction of cyclohexane carboxaldehyde and $p$ anisidine gave a mixture of products that were unstable on silica gel.

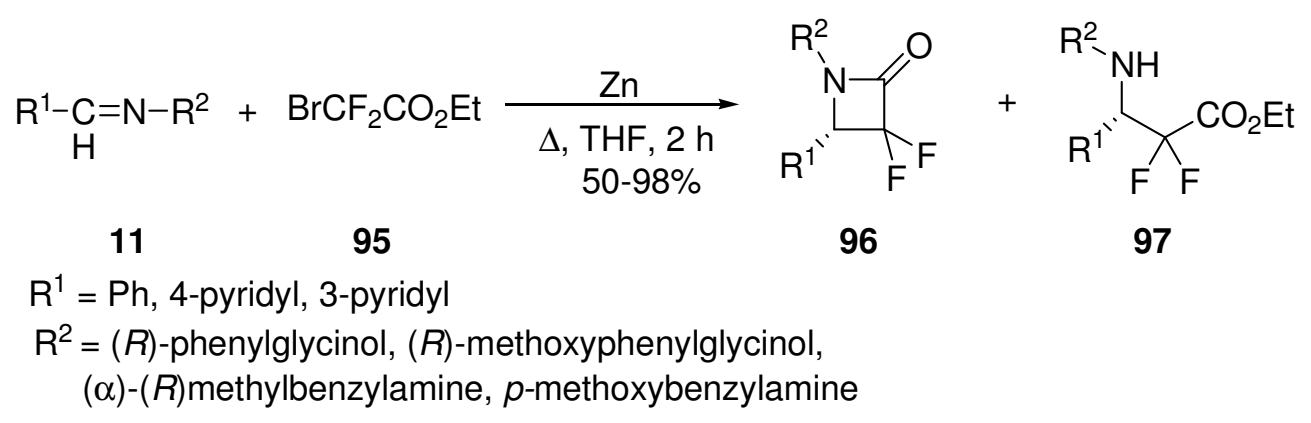

\section{Scheme 28}




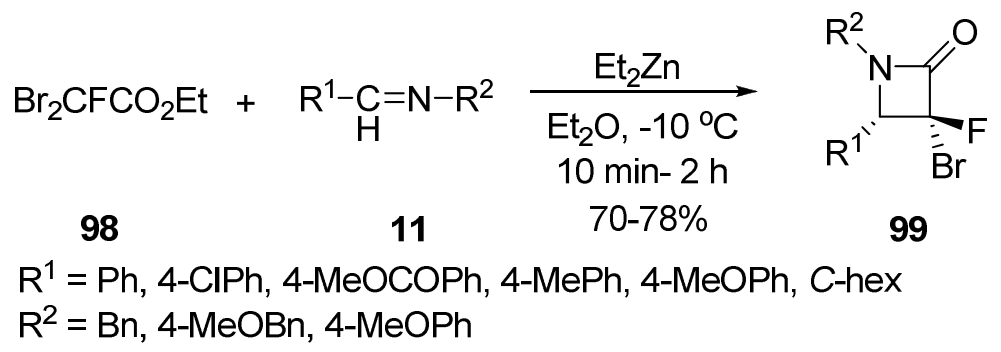

\section{Scheme 29}

Tarui and coworkers have reported an asymmetric synthesis of (S)-3,3-difluoro-2azetidinones 102 in moderate to good yields with high diastereoselectivity together with a $\beta$ amino ester 103 by the Reformatsky type reaction of (-)-menthyl bromodifluoroacetate 100 with imines 101 in the presence of $\mathrm{RhCl}\left(\mathrm{PPh}_{3}\right)_{3}$, followed by spontaneous elimination of the chiral auxiliary (Scheme 30). ${ }^{66}$ Among the imines of aromatic aldehydes, those bearing electrondonating groups offered higher enantioselectivity (ee 92-94\%) than those bearing electronwithdrawing groups (ee 80-87\%). Isobutyraldehyde imine in this reaction, however, afforded a racemate. Another enantioselective synthesis of 3-monosubstituted-, and 3,3-disubstituted 2azetidinones containing carbohydrate moiety has been reported via an indium-mediated reaction of imines and bromoesters. ${ }^{67}$ For example, the reaction of carbohydrate-derived imine 104 with 2-alkyl/phenyl-2-bromoesters $\mathbf{1 0 5}$ in the presence of indium led to the synthesis of 2azetidinones 106 (Scheme 31). The 2-azetidinone formation is stereoselective at the new nitrogenated stereocenter (C-4). An additional stereocenter is formed at C-3, hence a mixture of epimeric 2-azetidinones at $\mathrm{C}-3$, in which presumably the kinetically controlled product is the major isomer, is obtained.

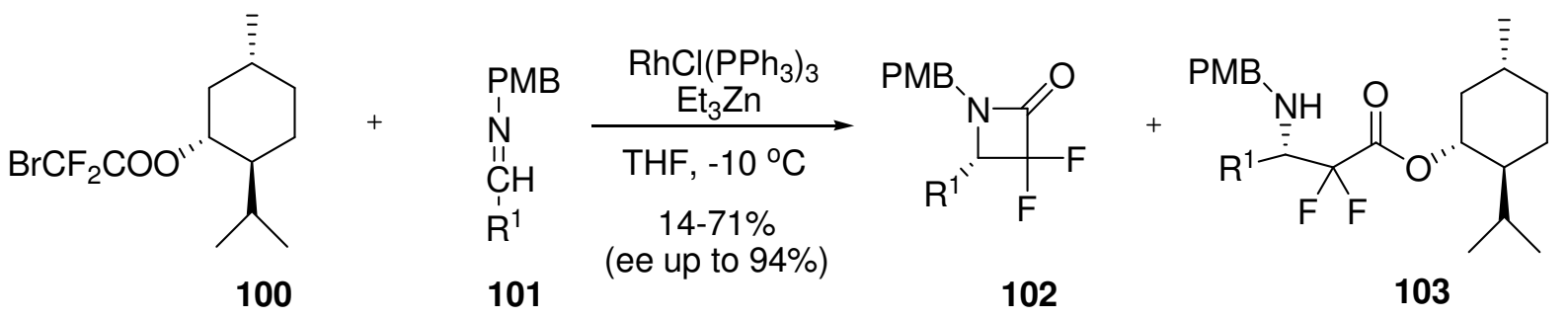

$\mathrm{R}^{1}=\mathrm{Ph}$, 1-naphthyl, 4-MeOPh, 4-CIPh, 4-COOMePh, C-hex, i-Pr

\section{Scheme 30}




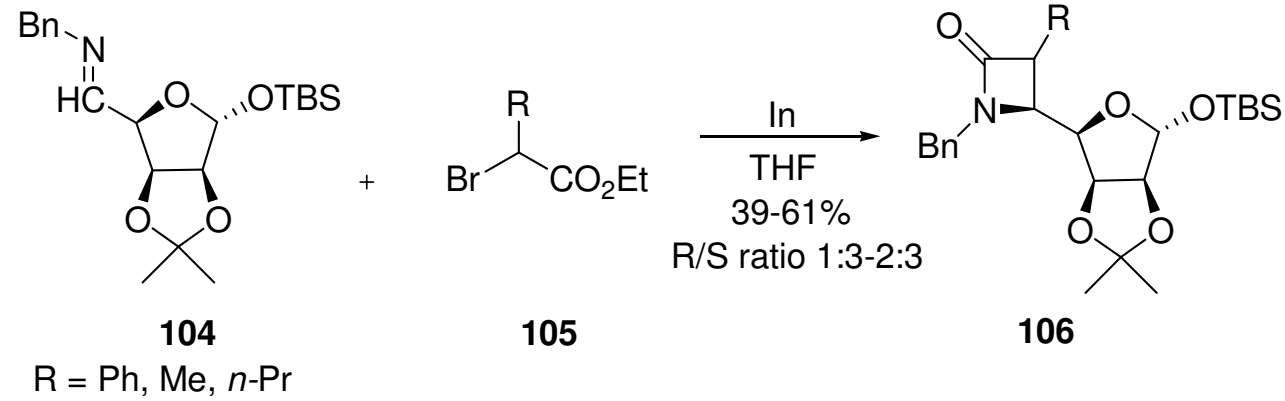

\section{Scheme 31}

A straightforward approach for the synthesis of $\beta$-lactams 109 in moderate to good yields and diastereomeric ratio ranging from 22:78 to 54:46 (cis:trans) by employing ETSA derivatives 108 was also reported. ${ }^{69}$ The latter compounds react with sodium salts of $N$-(2hydroxyphenyl)aldimines $\mathbf{1 0 7}$ in a THF-EtCN mixture (Scheme 32). This method has advantage over use of other ketene precursors like acyl chlorides or $\alpha$-diazocarbonyls because the hydroxyl group in imines needs not be protected.

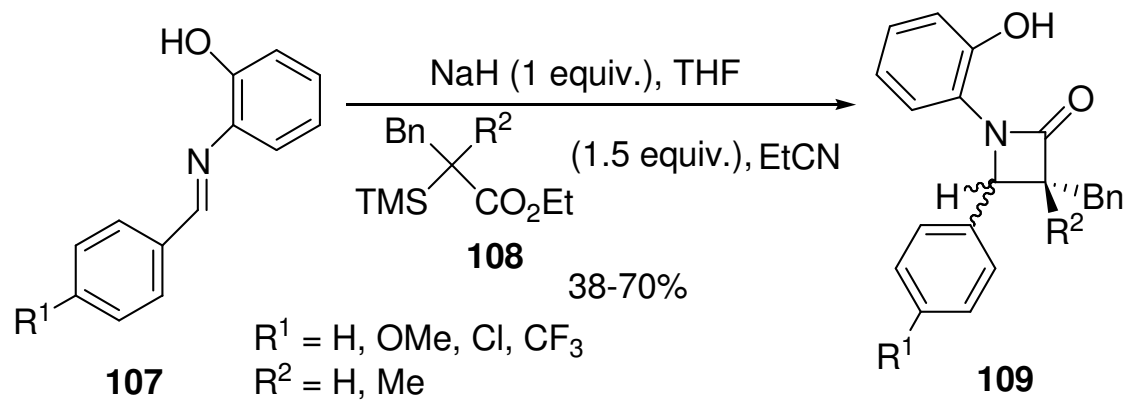

\section{Scheme 32}

The reaction of $\mathrm{N}$-substituted imines 110 of oxirane carboxaldehydes with in situ generated lithium ester enolates from symmetrically $\alpha$-disubstituted esters 111 and LDA has led to the diastereoselective synthesis of functionalized $\beta$-lactams 113 (de up to 99\%) through cyclization in intermediate 112 (Scheme 33). ${ }^{70}$ When the mono- $\alpha$-substituted esters were used as enolate precursors, unexpected side reactions occurred with loss of diastereoselectivity. This was attributed to the presence of the additional acidic proton next to the carbonyl group. An enantiomerically-enriched imine $(2 S, 3 S)$ gave the corresponding 2-azetidinone $\left(2 S, 3 S, 4^{\prime} R\right)$.

A three-step protocol for the synthesis of various functionalized gem-difluorinated $\beta$-lactams 118 in moderate to good yields has been developed by reactions between the Reformatsky reagent derived from ethyl bromodifluoroacetate 115 and the appropriate aldimines $114 .^{71}$ The 3,3-difluoro-2-azetidinones 116 were the major or the only isolated products except in the case of imine with a benzyloxy carbamate group. In the latter case, the $\beta$-lactam and $\beta$-amino ester 
118 were obtained in 1:1 ratio in good overall yield because the presence of a primary carbamate disfavored the cyclization step. Deprotection of the nitrogen atom in 2-azetidinones 116 using ceric ammonium nitrate $(\mathrm{CAN})$ leads to the formation of 2-azetidinones 117 with free $\mathrm{NH}$ (Scheme 34).

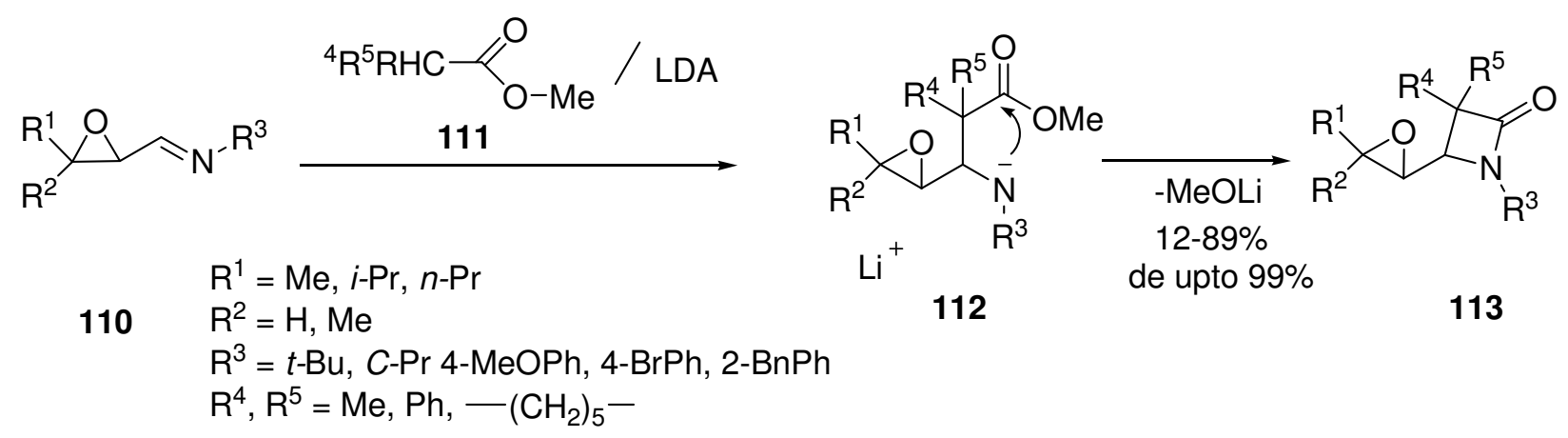

\section{Scheme 33}
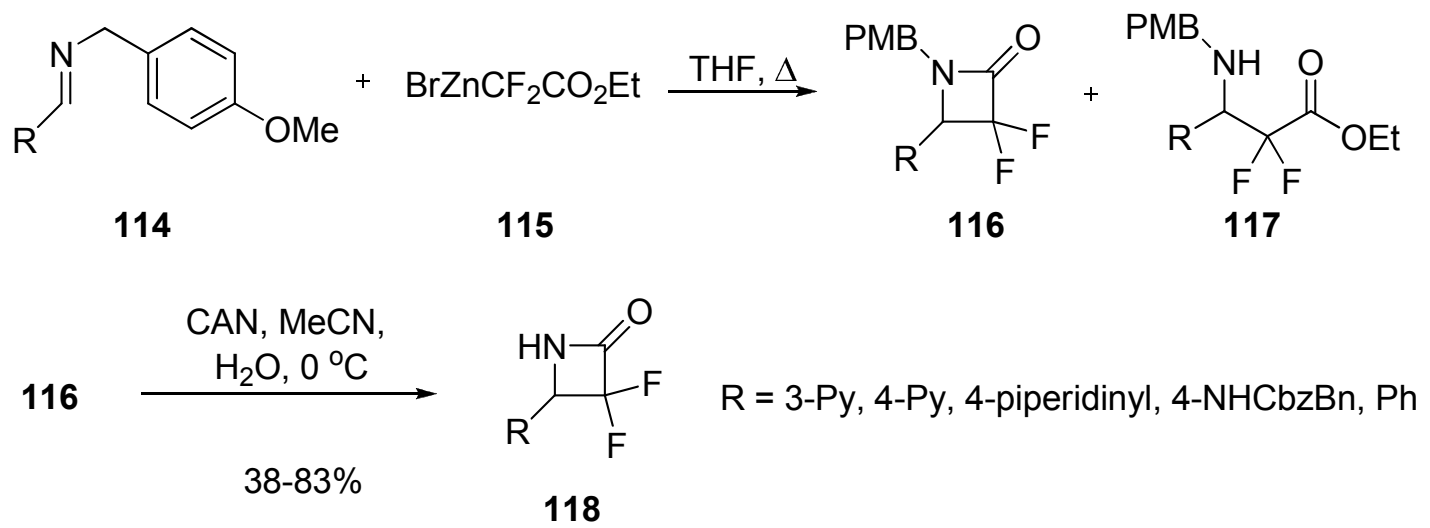

\section{Scheme 34}

\subsection{Alkyne-Nitrone Cycloadditions}

The alkyne-nitrone cycloadditions, commonly known as the Kinugasa reaction, has emerged as a powerful tool for the synthesis of diverse types of $\beta$-lactams. A formal synthesis of the powerful cholesterol inhibitor ezetimibe $\mathbf{1 2 4}$, based on a $\mathrm{Cu}(\mathrm{I})$-mediated Kinugasa cycloaddition/rearrangement is reported. ${ }^{72}$ The reaction of terminal alkyne 120, derived from acetonide of L-glyceraldehyde, with suitable $C, N$-diarylnitrone 119 is reported to form the 2azetidinone 121 (Scheme 35). The adduct (3R,4S)-2-azetidinone, obtained with high stereoselectivity, was subsequently subjected to opening of the acetonide ring to afford another 2-azetidinone 122. The glycolic cleavage in 2-azetidinone 122 led to formation of the 
azetidinone carboxaldehyde $\mathbf{1 2 3}$ which was transformed into ezetimibe by the Schering-Plough group. $^{73}$
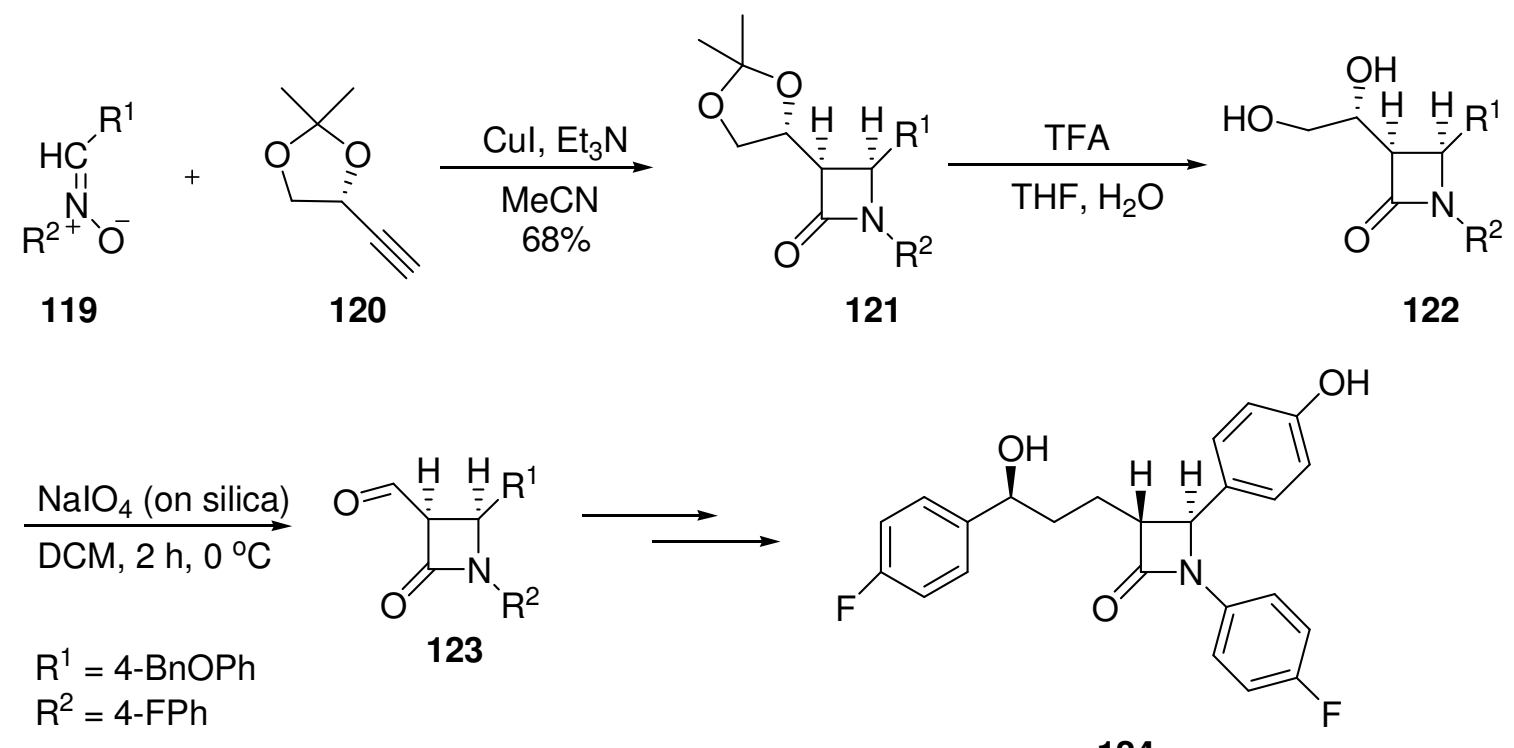

124

\section{Scheme 35}

The Kinugasa reaction has been efficiently carried out employing ynamides. ${ }^{74}$ The reaction of nitrones 119 with 3-ethynyloxazolidin-2-ones 125 led to highly stereoselective (dr 82:18 to $\geq$ 95:5) synthesis of chiral 3-amino-2-azetidinones 126 (Scheme 36). The application of this methodology has been demonstrated by reductive cleavage and subsequent Boc-protection in 126 resulting into formation of the 3-amino-2-azetidinone 127. Deprotection of $\mathrm{N}-1$ of the 2azetidinone 127 with CAN afforded NH 2-azetidinone 128.

Pezacki and coworkers have reported an "On water" application of Kinugasa reaction in 2azetidinones' synthesis by a micelle-promoted $\mathrm{Cu}(\mathrm{I})$-catalyzed multicomponent Kinugasa reaction. ${ }^{75}$ Reactions were performed for a series of in situ generated $C, N$-diarylnitrones with phenylacetylene $\mathbf{1 3 1}$ in the presence of copper sulfate in aqueous media yielding 2-azetidinones 132 in the range of $45-85 \%$ together with an amide $\mathbf{1 3 3}$ as a side product (Scheme 37). According to proposed mechanism, Na-ascorbate reduces the $\mathrm{Cu}$ (II) to $\mathrm{Cu}(\mathrm{I})$ and allows for in situ generation of $\mathrm{Cu}(\mathrm{I})$ phenylacetylide. This intermediate reacts with in situ generated nitrones from substituted benzaldehydes 129 and $N$-phenylhydroxyl amine 130 by a formal [3+2]cycloaddition forming an isoxazoline intermediate. Protonation of isoxazoline and subsequent rearrangement of the resulting oxaziridine produce a mixture of cis- and trans-2-azetidinones. The reaction is tolerant to substituents at the $\alpha$-aryl position of the nitrone, and higher yields of $\beta$-lactams were obtained when electron-withdrawing substituents were employed. 


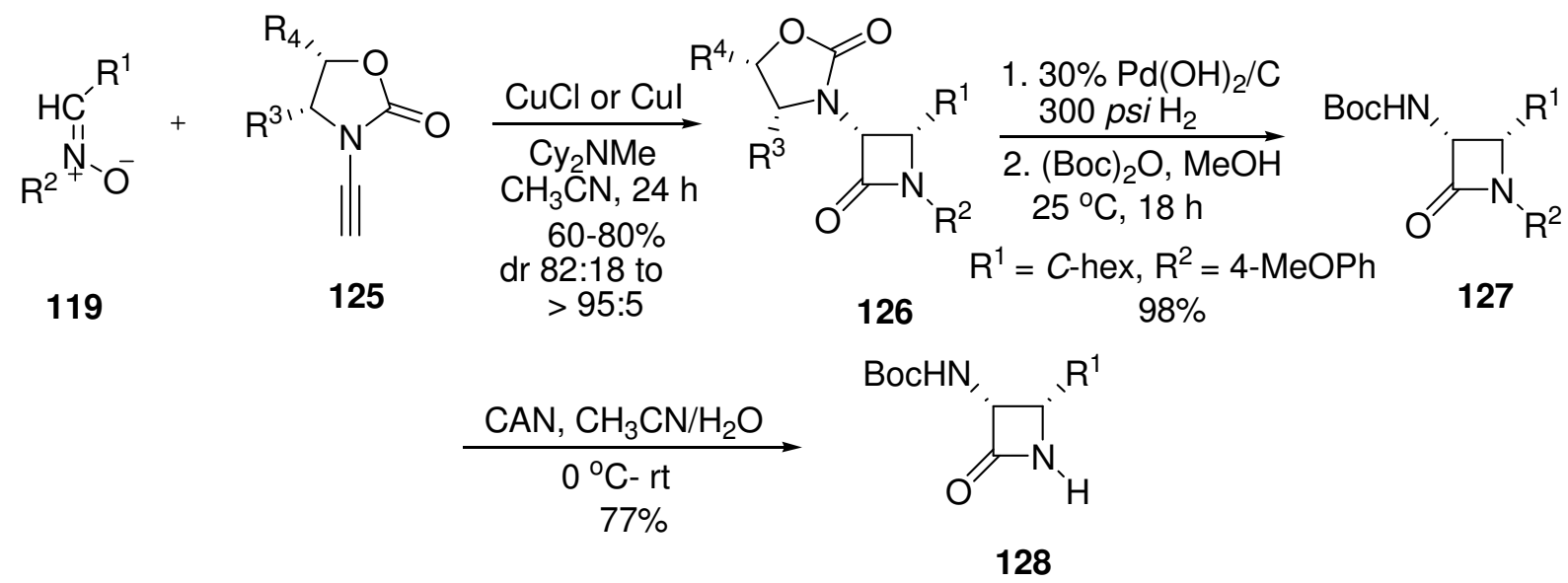

$\mathrm{R}^{1}=4$-BrPh, 1-naphthyl, styryl, 2-furyl, 2-thienyl, $\mathrm{Ph}, \mathrm{C}$-hex

$\mathrm{R}^{2}=\mathrm{Ph}, 4-\mathrm{MeOPh}, 4-\mathrm{CIPh}, 4-\mathrm{COEt}$

$\mathrm{R}^{3}=\mathrm{Ph}, i-\mathrm{Pr}, \mathrm{CHPh}_{2}, \mathrm{Bn}$

$\mathrm{R}^{4}=\mathrm{Ph}, \mathrm{H}, \mathrm{Me}$

\section{Scheme 36}<smiles></smiles><smiles>ONc1ccccc1</smiles>

130

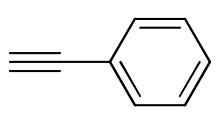

131

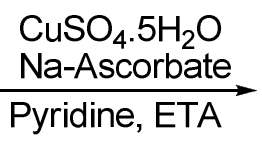

$\mathrm{SDS} / \mathrm{H}_{2} \mathrm{O}$

$0^{\circ} \mathrm{C}$ to $\mathrm{rt}, 10 \mathrm{~h}$

$45-85 \%$

$\mathrm{X}=\mathrm{H}$, 4-Me, 4-OMe, 2-OMe, 4-Br, 4-CO $\mathrm{CO}_{2} \mathrm{Me}, 4-\mathrm{CN}, 2-\mathrm{NO}_{2}, 4-\mathrm{NO}_{2}$

\section{Scheme 37}

Treatment of the chiral propargylic alcohols and ethers 134 with diaryl nitrones 119 furnished mainly the cis $\beta$-lactams 135 (Scheme 38). ${ }^{76}$ The subsequent oxidation/epimerization of the cis-adduct by treatment with PCC afforded the trans isomer. For the first time, the unprotected chiral propargylic alcohols have also been utilized in the Kinugasa reaction.

The asymmetric version of this reaction has been carried out by using nitrones $\mathbf{1 3 6}$ and terminal alkynes $\mathbf{1 3 7}$ in the presence of copper complex of (S)-4-tert-butyl-2-[3(diphenylphosphino)thiohen-2-yl]-4,5-dihydrooxazole $\mathbf{1 3 8}$ as a catalyst to afford the 2azetidinones 139 and $\mathbf{1 4 0}$ in good diatereoselectivity but moderate enantioselectivity (Scheme 39). ${ }^{77}$ Diastereoselectivity of the products depends on the nature of the alkynes. Most alkynes 
afforded the cis-adducts except 3,5-trifluoromethylacetylene which furnished trans-adducts. Very recently, Chen and coworkers have reported chiral tris(oxazoline)] 142/Cu(I) complex as a novel efficient catalyst for an asymmetric Kinugasa reaction of terminal alkynes 141 with $C$-aryl nitrones 119 to afford the 2-azetidinones 143 and 144 in highly diastereo- and enantioselective manner (Scheme 40). ${ }^{78}$ Another highly enantioselective Kinugasa reaction of nitrones 136 with terminal alkynes 145 in the presence of bis-oxazoline 146/Cu(OTf $)_{2}$ and dibutylamine has been reported to yield 2-azetidinones 147 and 148 (Scheme 41). ${ }^{79}$ The scope of alkyne-nitrone cycloadditions has been further expanded by Sierra and coworkers who used ferrocene- and ruthecene-containing alkynes to synthesize metal-containing 2-azetidinones. ${ }^{80}$
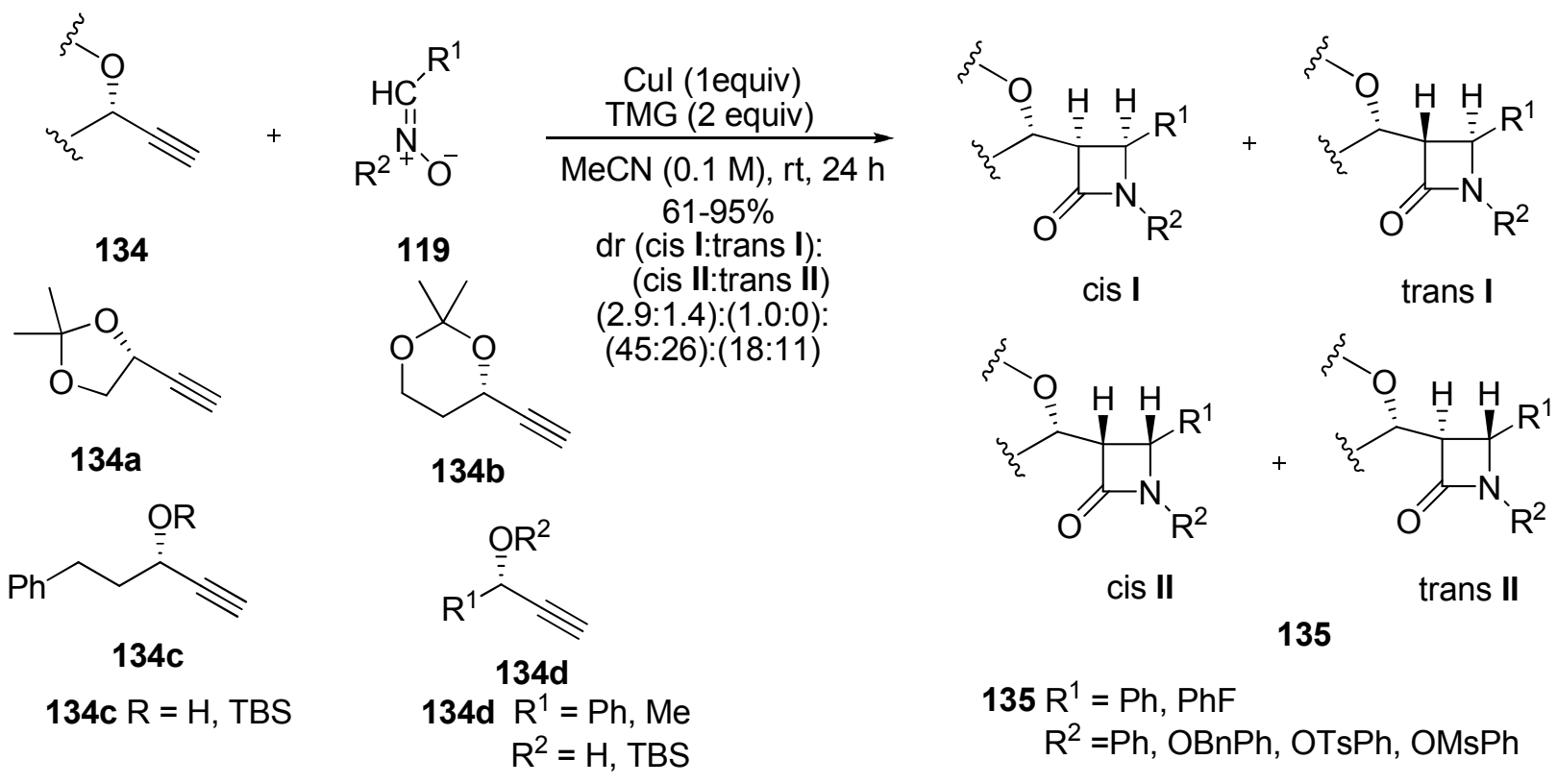

\section{Scheme 38}
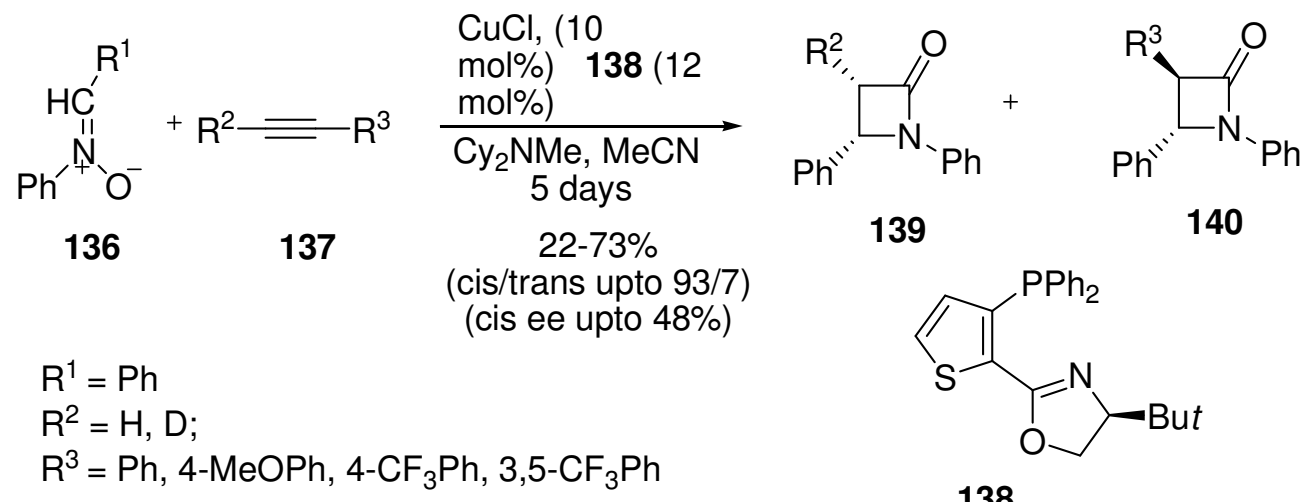

\section{Scheme 39}




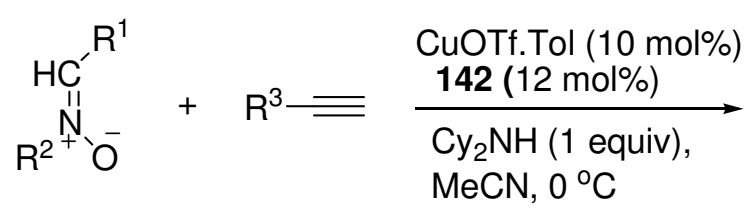

$$
\begin{aligned}
& 119 \\
& 141 \\
& 34-98 \% \\
& \text { (cis/trans upto } 97 / 3 \text { ) } \\
& \text { (cis ee upto 99\%) }
\end{aligned}
$$<smiles>[R7]C1[C@H]([R7])C(=O)N1[R7]</smiles>

143
144

$\mathrm{R}^{1}=\mathrm{Ph}$, 4-MePh, 4-MeOPh, 4-FPh, 4-CIPh, 4- $\mathrm{CF}_{3} \mathrm{Ph}$, 4- $\mathrm{NO}_{2} \mathrm{Ph}, 4-\mathrm{MePh}, 4-\mathrm{MeOPh}, \alpha$-furyl

$\mathrm{R}^{2}=\mathrm{Ph}, 4-\mathrm{MeOPh}, 4-\mathrm{MePh}, 4-\mathrm{EtO}_{2} \mathrm{CPh}, 4-\mathrm{BrPh}$

$\mathrm{R}^{3}=\mathrm{Ph}, 4-\mathrm{BrPh}, 4-\mathrm{MeOPh}, 4-\mathrm{MePh}, \mathrm{C}$-hex, $n$-pentyl<smiles>CC(CC1=N[C@H](C(C)(C)C)CO1)(C1=N[C@@H]2Cc3ccccc3[C@H]2C1)C1=N[C@H]2c3ccccc3C[C@H]2O1</smiles>

\section{Scheme 40}<smiles>[R]C=[N+]([O-])c1ccccc1</smiles>

136<smiles>CC(C)(C)c1ccc2c(c1)C[C@H]1OC(CC3=N[C@@H]4c5ccccc5CC4O3)=N[C@H]21</smiles>

$$
\begin{gathered}
\mathrm{Cu}(\mathrm{OTf})_{2}(20 \mathrm{~mol} \%) \\
146(22 \mathrm{~mol} \%)
\end{gathered}
$$

(cis/trans upto 87/13)

(cis ee upto 94\%)<smiles>[R]C1C(=O)C(=O)N1c1ccccc1</smiles>

147<smiles>[R]C1C(c2ccccc2)C(=O)N1c1ccccc1</smiles>

148

\section{Scheme 41}

\subsection{Alkene-Isocyanate Cycloadditions}

The cycloaddition of vinyl acetate 149 and chlorosulfonyl isocyanate 150 has been employed recently by Lee in the synthesis of 3-isopropylthio-2-azetidione 154 (Scheme 42) ${ }^{81}$ After in situ reductive removal of the chlorosulfonyl group from the 2-azetidinone 151, the resulting 2azetidinone 152 was thioalkylated using sodium isopropylthiolate 153 to yield the 2-azetidinone 154. 


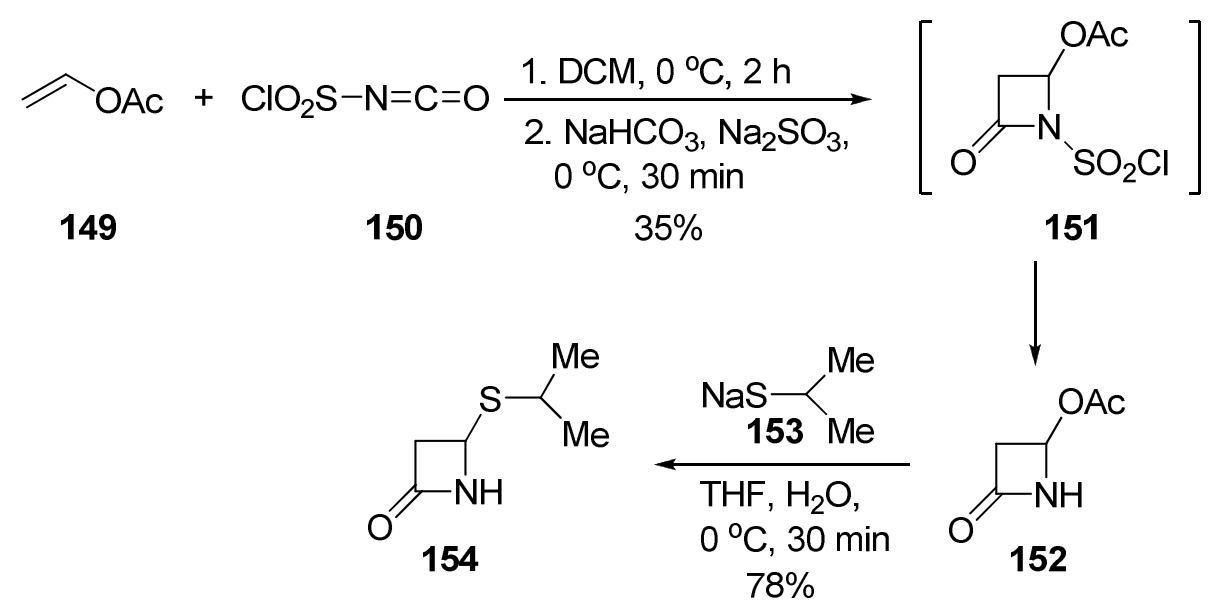

\section{Scheme 42}

\subsection{Torii's Cyclocarbonylation of Allyl halides with Imines}

The imines react with allyl bromide by [2+2]-cycloaddition under $\mathrm{CO}$ pressure in the presence of $\mathrm{Et}_{3} \mathrm{~N}, \mathrm{Pd}(\mathrm{OAc})_{2}$ and $\mathrm{Ph}_{3} \mathrm{P} .{ }^{82}$ Imines conjugated with a carbonyl group furnish cis-2-azetidinones whereas the nonconjugated imines afford trans-2-azetidinones. ${ }^{83,84}$ The synthesis of 2azetidinones 155 and 156 with high diastereoselectivity is reported by a palladium-catalyzed [2+2]-carbonylative cycloaddition of allyl bromide with $\mathrm{N}$-alkyl imines $\mathbf{1 1}$ of benzaldehyde and many other heteroaromatic aldehydes (Scheme 43). ${ }^{85}$ An efficient carbonylative [2+2]cycloaddition of benzyl halides and phosphates with imines 11 in the presence of $\left[(\mathrm{Bmim}) \mathrm{PdI}_{2}\right]_{2}$ catalyst leading to the formation of 2-azetidinones 157 in a highly stereoselective manner (trans/cis ratio up to $>95 / 5$ ) with up to $96 \%$ yield is reported (Scheme 44). ${ }^{86}$ 3,4-Diaryl 2azetidinones 158 have been prepared with high stereoselectivity via palladium-catalyzed [2+2]carbonylative cycloaddition of benzyl halides with $\mathrm{N}$-benzylideneamines and many other $N$-heteroarylideneamines 11 (Scheme 45). ${ }^{87}$ It appeared that the substituent on nitrogen atom of the imines influenced the stereoselectivity. The phenyl and the $n$-butyl groups led to cyclization toward the formation of the trans isomer. Conversely, the bulky tert-butyl group favored the cyclization toward the cis isomer.

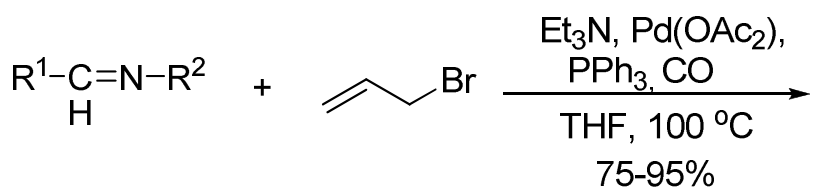

11

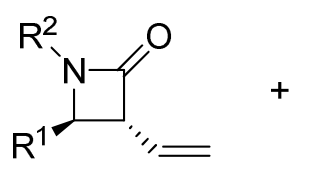

155

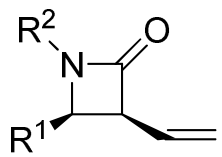

156

$\mathrm{R}^{1}=\mathrm{Ph}, 2$,4-dimethylthiazole, 2-methylbenzothiazole, 4-MePy, 2-MePy, 3-MePy

$\mathrm{R}^{2}=t-\mathrm{Bu}, n-\mathrm{Bu}, i-\mathrm{Pr}, \mathrm{Et}$

\section{Scheme 43}




$$
\begin{aligned}
& \underset{\mathrm{H}}{\mathrm{R}^{1}-\mathrm{C}=\mathrm{N}-\mathrm{R}^{2}}+\mathrm{RCH}_{2} \mathrm{X} \underset{\substack{\mathrm{CO}(30 \mathrm{~atm}) \\
100^{\circ} \mathrm{C}, 24 \mathrm{~h}}}{\stackrel{\left[(\mathrm{Bmmim}) \mathrm{Pdl}_{2}\right]_{2}}{i-\mathrm{Pr}_{2} \mathrm{NEt}}} \\
& 11 \\
& \mathrm{MeCN} \\
& 157 \\
& \mathrm{X}=\mathrm{Cl}, \mathrm{Br}, \mathrm{OP}(\mathrm{O})(\mathrm{OEt})_{2} \\
& 61-96 \% \\
& \mathrm{R}=\mathrm{Ph}, 4-\mathrm{ClPh}, 4-\mathrm{BrPh} \text {, 4-MePh, 2-MeOPh, 4-MeOPh, 1-Naphthyl } \\
& \mathrm{R}^{1}=\mathrm{Ph}, 4-\mathrm{CIPh} 4-\mathrm{BrPh} \text {, 4-MePh, 2-MeOPh, 2,3- } \mathrm{MeO}_{2} \mathrm{Ph} \text {, } \\
& \text { 4- } \mathrm{Me}_{2} \mathrm{NPh}, 1-\mathrm{Naphthyl},(E)-\mathrm{PhCH}=\mathrm{CH} \\
& \mathrm{R}^{2}=\mathrm{Bn}, \mathrm{Ph}, n-\mathrm{Pr}, \mathrm{CH}_{2} \mathrm{CO}_{2} \mathrm{Me}
\end{aligned}
$$

\section{Scheme 44}

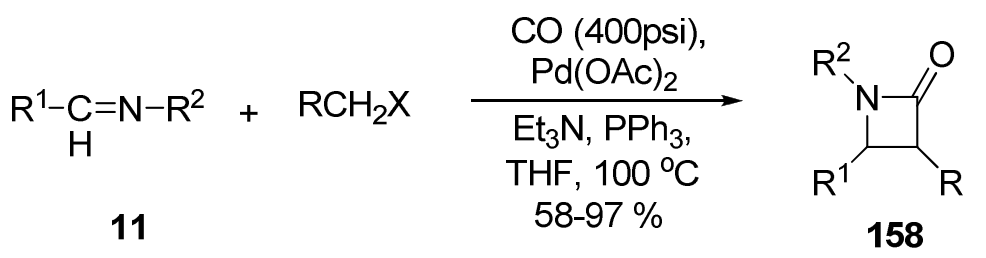

$$
\begin{aligned}
& \mathrm{R}=\mathrm{Ph}, 2,4-\mathrm{Me}_{2} \mathrm{Ph}, 2-\mathrm{Me}, 4-\mathrm{MeOPh} \\
& \mathrm{R}^{1}=\text { 2,4-dimethylthiazole, 2-methylbenzothiazole, 2-MePy, 4-MePy, } \mathrm{Ph} \\
& \mathrm{R}^{2}=\mathrm{Ph}, n-\mathrm{Bu}, t-\mathrm{Bu} \\
& \mathrm{X}=\mathrm{Br}, \mathrm{Cl}
\end{aligned}
$$

\section{Scheme 45}

\subsection{Expansion of Aziridine Rings}

The palladium-catalyzed carbonylative ring expansion of vinyl aziridines $\mathbf{1 5 9}$ is reported to yield the 2-azetidinones 160 (Scheme 46). ${ }^{88}$ The 2-azetidinones 160c was the predominant diastereomer ( $\mathrm{dr}$ 76-100\%) with cinamyl aziridines as substrate. The reversal of diastereoselectivity to cis isomer $\mathbf{1 6 0 b}$ was possible at high pressure of $\mathrm{CO}$, low $\mathrm{Pd}$ concentration and low temperature. A methyl-substituted vinyl aziridine decomposed under standard reaction conditions but yielded the trans 2-azetidinone 160a at 50 bar pressure of $\mathrm{CO}$. The reaction involved a $\mathrm{Pd}(0)$-mediated isomerization of vinyl aziridines followed by carbonylation and ring closure. 


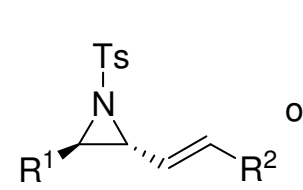

$159 a$<smiles>[R]C=CC1[C@@H]([3H])N1[3H]</smiles>

$159 b$

$$
\mathrm{Pd}_{2}(\mathrm{dba})_{3} \cdot \mathrm{CHCl}_{3}(5 \mathrm{~mol} \%)
$$
$\mathrm{PPh}_{3}$ (0.6 equiv.) CO (1bar) PhMe, rt, 2 h $59-77 \%$

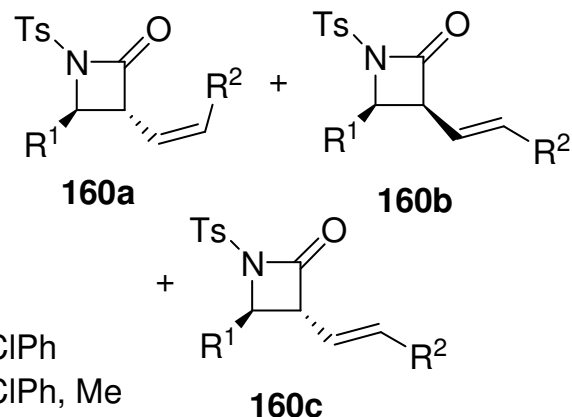

\section{Scheme 46}

Wulff and coworkers have published their study on reactions of aziridine-2-carboxylic acids 161 with oxalyl chloride under different conditions. ${ }^{89}$ This group observed exclusive formation of 2-azetidinones 162 in case of aziridines containing an alkyl group on C-3 position (Scheme 47). The reactions of $c i$-aziridines led to the formation of $c i s$-2-azetidinones and trans-aziridines led to the formation of trans-2-azetidinones; thus the reaction is stereospecific.

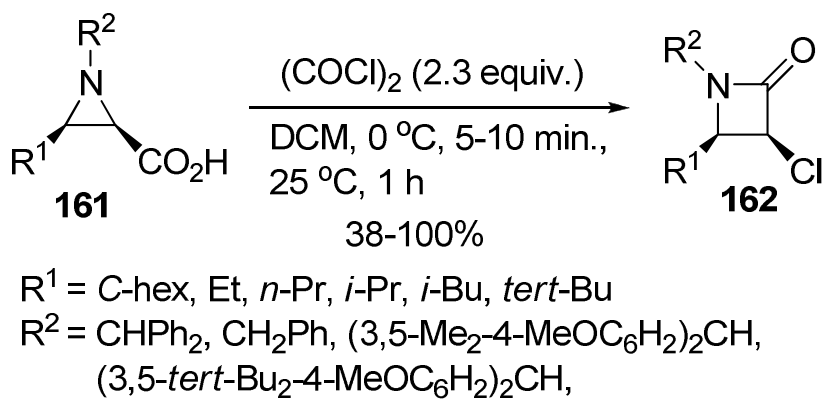

\section{Scheme 47}

\subsection{Cyclization by Formation of $\mathrm{N}_{1}-\mathrm{C}_{2}$ Bond}

1 '-Aminoalkyldioxolan-4-ones $\mathbf{1 6 4}$, obtained by an acid-induced removal of sulfinyl protecting group from the 1'- $N$-sulfinylaminoalkyl-dioxolan-4-ones 163, are reported to undergo cyclization affording chiral 3-hydroxy-2-azetidinones $\mathbf{1 6 5}$ in good yields and excellent diastereoselectivity (Scheme 48). ${ }^{90}$ The base-induced cyclization in the unprotected dioxolan-4ones 164 by nucleophilic attack of the amino group on carbonyl carbon followed by dioxolane ring opening and hydrolysis of the resulting ester has been reported to afford the final products. 
<smiles>[R7]C(N[S@](=O)C(C)(C)C)[C@]1([R7])O[C@@]([R7])(Br)OC1=O</smiles>

163<smiles>[R7]C(N)C1([R])OC([R7])(Br)OC1=O</smiles>

164<smiles>[R]C1([R])NC(=O)[C@]1([R7])O</smiles>

165

$\mathrm{R}=\mathrm{Me}, \mathrm{Ph} ; \mathrm{R}^{1}=\mathrm{Me}, \mathrm{H} ; \mathrm{R}^{2}=\mathrm{Me}, \mathrm{Et}, n-\mathrm{Pr}, n-\mathrm{Oct} ; \mathrm{R}^{3}=\mathrm{Me}$, Et, $n$-Pr, $n$-Oct

\section{Scheme 48}

In the next example, the $\beta$-amino esters 169 have been cyclized in the presence of LDA to furnish the corresponding 2-azetidinones 170 with high optical purity (Scheme 49). ${ }^{91}$ The $\beta$ amino esters were accessed by the highly diastereoselective direct Mannich-type reaction of dimethyl malonate 166 with $N$-(tert-butyl)sulfinyl imines 167 under solvent-free conditions using $\mathrm{NaHCO}_{3}$ or $\mathrm{NaI}$ as base promoters and deprotection of the $N$-tert-butylsulfinyl group from the resulting adducts $\mathbf{1 6 8}$.

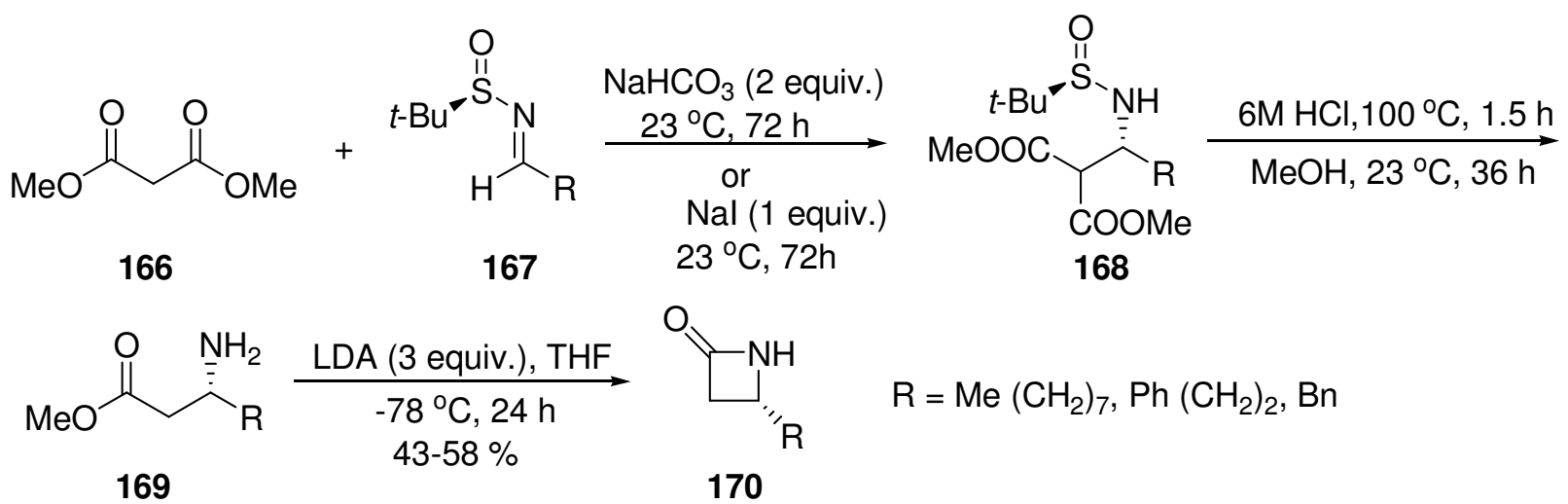

\section{Scheme 49}

Kashikura and coworkers have developed a catalytic enantioselective Mannich-type reaction of aldimines 76 with difluoroenol silyl ether 171 by employing biphenol-derived chiral phosphoric acid 172 (Scheme 50). ${ }^{92}$ The resulting Mannich adduct, an $\alpha$-gem-difluoro- $\beta$-amino ketone 173 furnished the corresponding $\beta$-amino ester 174 without loss of enantioselectivity on treatment with $m$-CPBA in DCM/HFIP (hexafluoroisopropanol) in the presence of aqueous phosphate buffer. Deprotection of amino group in this ester and the subsequent base-promoted cyclization afforded the 3,3-difluoro-4-phenylazetidin-2-one 175 (Scheme 50). Melchiorre and coworkers have reported cyclization of aspartic acid derivative $\mathbf{1 7 6}$ leading to enantioselective synthesis of 2-azetidinones (Scheme 51). ${ }^{93}$ The protection of $\mathrm{NH}$ group in 2-azetidinone 177 with Boc group afforded $(3 R, 4 S)-N$-Boc-2-azetidinone $\mathbf{1 7 8 .}$ 


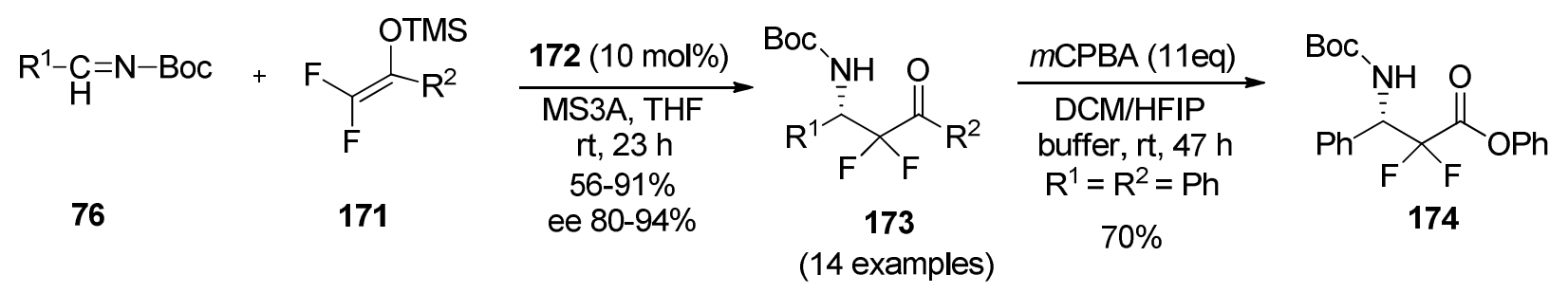

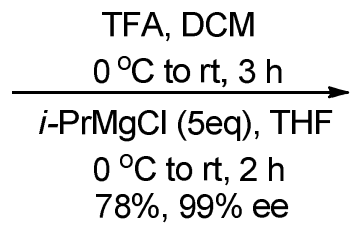

$78 \%, 99 \%$ ee

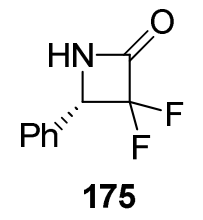

R=9-anthryl

172

\section{Scheme 50}



\section{Scheme 51}

The cyclization of $\beta$-amino alcohols 182, formed in situ by catalytic hydrogenolysis of the fluorinated isoxazolidines $\mathbf{1 8 1}$, has led to the formation of $\alpha$-trifluoromethyl-2-azetidinones $\mathbf{1 8 3}$ in good to excellent yields (Scheme 52). ${ }^{94}$ The isoxazolidines were, in turn, synthesized by 1,3 dipolar cycloaddition of nitrones $\mathbf{1 7 9}$ with fluorinated alkenes $\mathbf{1 8 0}$.

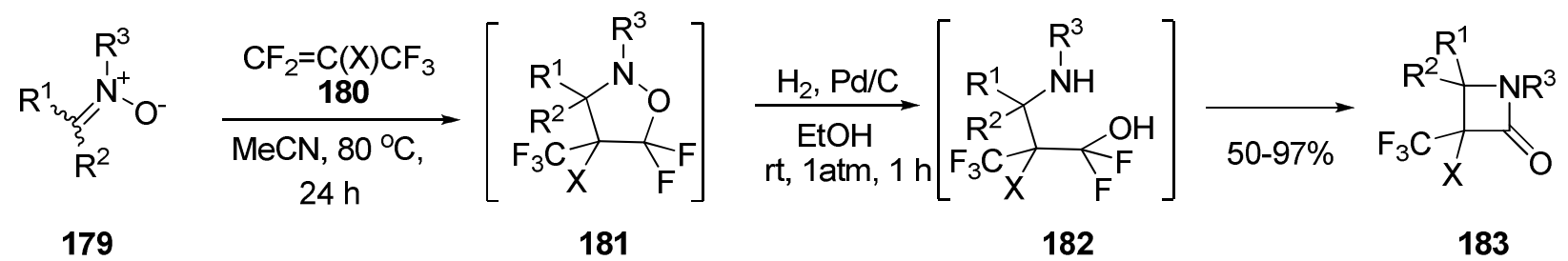

$\mathrm{R}^{1}=$ aryl, heteroaryl; $\mathrm{R}^{2}=\mathrm{H}, \mathrm{Ph} ; \mathrm{R}^{3}=\mathrm{Me},-\left(\mathrm{CH}_{2}\right)_{3} \mathrm{OH}$

$\mathrm{X}=\mathrm{H}, \mathrm{F}$

\section{Scheme 52}

An excellent methodology for stereodivergent synthesis of both cis and trans- $\beta$-lactams has been developed by cyclization of $\alpha$-aminoketenes $189 .{ }^{95}$ The synthesis originates from an 
addition of alkynyl imines $\mathbf{1 8 4}$ to ketene silyl acetals 185 forming iminocyclobutenones 186 (Scheme 53). A chemoselective reduction of azomethine linkage in iminocyclobutenones 186 by sodium cyanoborohydride affords aminocyclobutenones 187 that rearrange to $\alpha$-aminoketenes 189 in the presence of amine bases 188. The ketenes that cyclize by intramolecular nucleophilic addition of the amino group to the carbonyl carbon furnish either cis or trans- $\beta$-lactams 190 and 191, respectively, depending on the nature of the base used. Application of 1,4-dimethyl- and 1,4-diethylpiperazines 188a led to the formation of cis- $\beta$-lactams 190 while in the presence of stronger bases such as DBN and DBU 188b, the cis- $\beta$-lactams isomerized into thermodynamically more stable trans- $\beta$-lactams 191 (Scheme 53).



\section{Scheme 53}

Another methodology based on cyclization of $\alpha$-aminoketenes is reported by employing an $\alpha$-diazo- $N$-methoxy- $N$-methyl (Weinreb)- $\beta$-keto amide, containing an amino group at an appropriate position, as ketene precursor. ${ }^{96}$ The formation of enantiometrically pure 2azetidinones 195 and 196 was observed on photolysis of $\alpha$-diazo- $N$-methoxy- $N$-methyl (Weinreb) $\beta$-ketoamide 192 (Scheme 54). Both MVL (Medium pressure mercury vapor lamp) and CFL (continuous flow lamp) were utilized to promote the photolysis; the latter afforded a safe and environment-friendly alternative to standard photolysis conditions. The mechanism involved the cyclization of in situ generated ketene 193 through the 2-hydroxyazetine 194. The diastereoselectivity was observed to vary from the modest to nearly complete. 
<smiles>CON(C)C(=O)C(=NC(COCc1ccccc1)c1ccccc1)C(=O)Cc1ccccc1</smiles>

192<smiles>CON(C)C(=O)C(=C=O)C(COc1ccccc1)Nc1ccccc1</smiles>

193

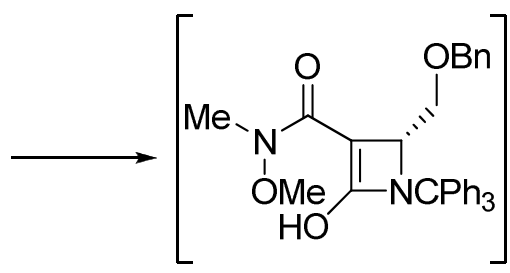

194

Yield MVL flow 81\% (trans:cis 61:20) CFL flow $91 \%$ (trans:cis 70:21)

\section{Scheme 54}

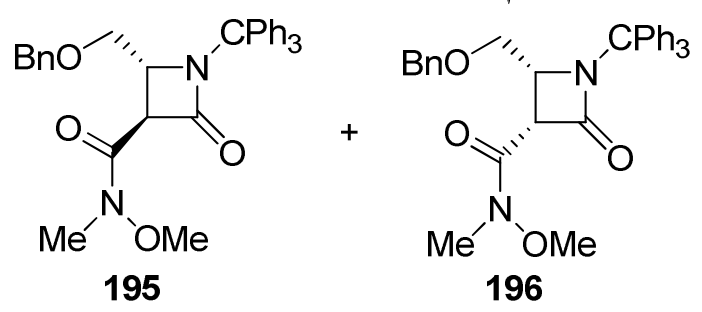

Decomposition of the $\alpha$-diazo $\beta$-ketoamides 198, derived from $\operatorname{Tr}-\mathrm{Ser}(\mathrm{OBn})-\mathrm{OH}$ 197, under photochemical or rhodium catalysis afforded the ketene intermediate $\mathbf{2 0 0}$ by the Wolff rearrangement of rhodium carbenoid 199 (in case of rhodium catalysis) (Scheme 55). ${ }^{97}$ The ketene undergoes intramolecular attack by the trityl-protected amine to provide the trans-tritylprotected $\beta$-lactams 201. The amino acid stereocenter was incorporated, the second chiral center was induced, and trityl protection of the $\beta$-lactam ring has been realized for the first time. This is the direct formation of the $\beta$-lactam nucleus from $\alpha$-amino acids.

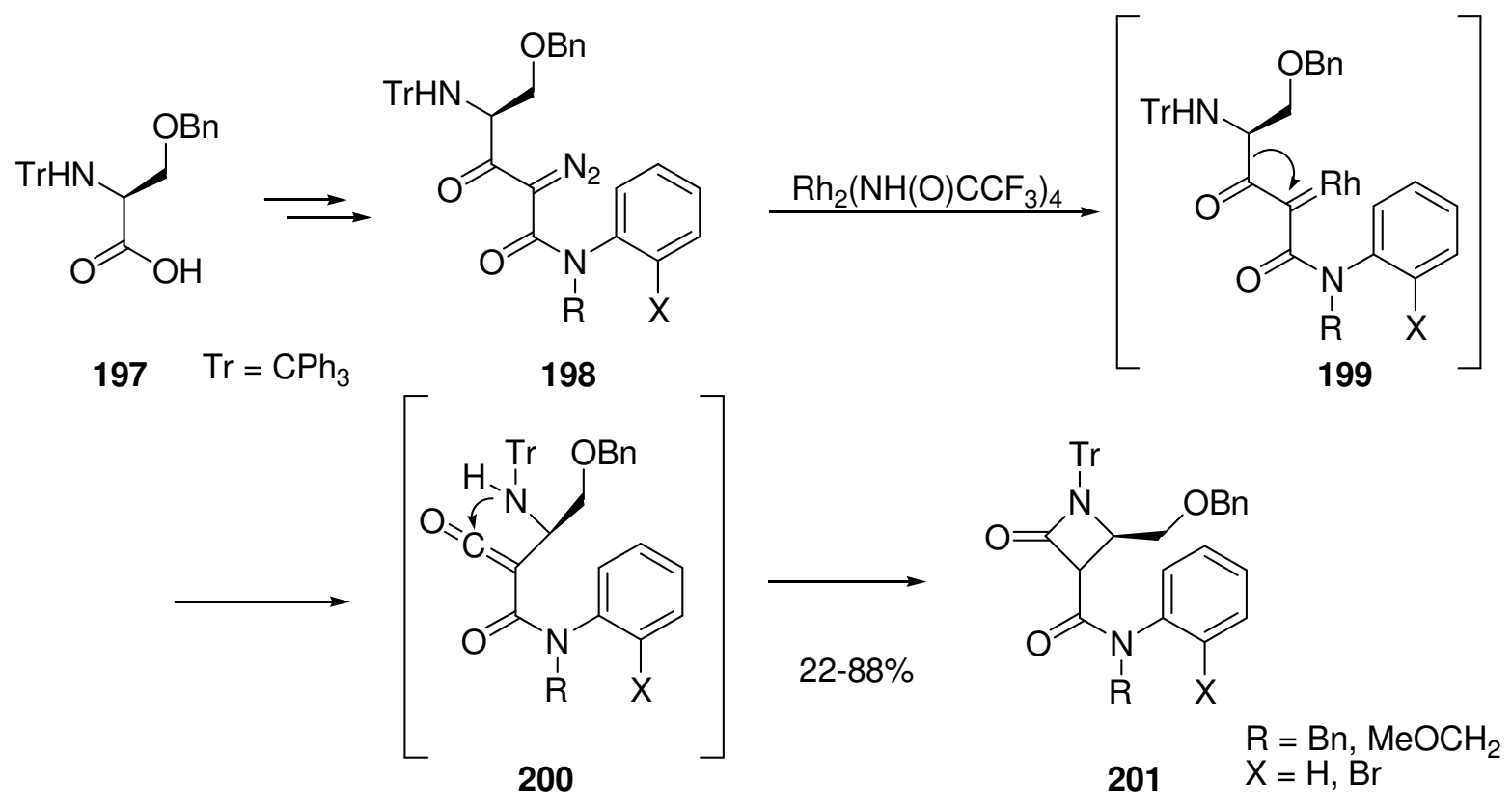

\section{Scheme 55}




\subsection{Cyclization by Formation of $\mathrm{N}_{1}-\mathrm{C}_{4}$ Bond}

L-Cysteine-derived thiazolidine hydroxamate esters $\mathbf{2 0 2}$ are cyclized to the thiazolidine-fused 2azetidinones 203 using methyl sulfonyl chloride. ${ }^{98}$ The cleavage of the thiazolidine ring with methoxycarbonylsulfenyl chloride afforded the monocyclic $\beta$-lactam 205 in 65\% yield (Scheme 56). Attempts to deprotect the nitrogen in $\beta$-lactam 205 using $\mathrm{LAH}, \mathrm{NaBH}_{4}, \mathrm{Zn}$ powder, etc. and obtain the $\beta$-lactam 204 proved futile due to cleavage of N1-C4 bond of the $\beta$-lactam ring. Ultimately the $\beta$-lactam 204 could be accessed by first deprotection of the nitrogen in thiazolidine-fused $\beta$-lactam 203, and then cleavage of the thiazolidine ring in it.

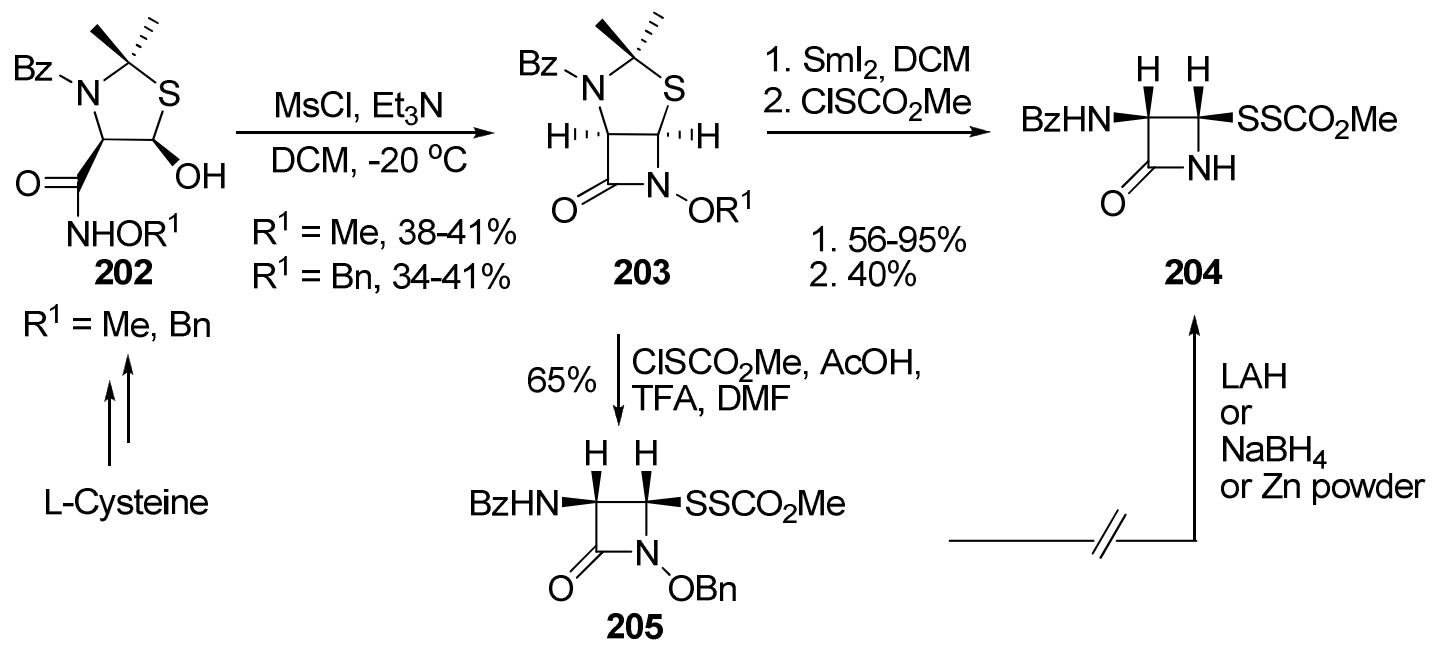

\section{Scheme 56}

A NaOH-promoted intramolecular aza-Michael addition of $\alpha$-carbamoyl, $\alpha-(1-$ chlorovinyl)ketene-S,S-acetals $\mathbf{2 0 6}$ followed by the nucleophilic vinylic substitution reaction yielded 1,4,4-trisubstituted 3-alkylidene-2-azetidinones 209. ${ }^{99}$ An intramolecular aza-Michael addition of the nitrogen atom to the unsaturated $\beta$-carbon of ketene-S,S-acetals 206 under basic conditions, generates carbanionic intermediates 207, which subsequently undergo protonation reaction in alcoholic aqueous media to afford the intermediate products 208 (Scheme 57). Finally, the displacement of chloride in compounds $\mathbf{2 0 8}$ by alkoxide ion via nucleophilic vinylic substitution reaction gives rise to 2-azetidinones 209 in $41-94 \%$ yields. In most of the cases only (E)-isomer was obtained. The cyclization was successful in ethanol and methanol but not in tertbutanol presumably due to steric effect and low nucleophilicity of tert-butoxide. 
<smiles>[R7]NC(=O)/C(C(=C)Cl)=C(\[R5])[Sn](C)O</smiles>

206<smiles>[R]OCC1=C(Cl)C([R5])([R5])N([R])C1=O</smiles><smiles>[R]N1C(=O)C(C(=C)Cl)C1([R7])[R6]</smiles>

207<smiles>[R1]N1C(=O)C(=C(C)Cl)C1([R5])S</smiles>

208

$\mathrm{R}^{1}=\mathrm{Ph}, 4-\mathrm{MePh}$, 4-MeOPh, 4-CIPh, 2,4-Me ${ }_{2} \mathrm{Ph}, \mathrm{Me}$

$\mathrm{R}^{2}=\mathrm{Me}$, Et

$\mathrm{R}^{3}=\mathrm{Et}, \mathrm{Me}, i-\operatorname{Pr}, t-\mathrm{Bu}$

\section{Scheme 57}

Zhao and Li have reported a highly efficient method for the synthesis of 4-alkylidene-2-azetidinones 211 via a copper-catalyzed intramolecular C-N coupling in 3-bromo-but-3-enamides 210 (Scheme 58). ${ }^{100}$ Under $\mathrm{Cu}(\mathrm{I})$ catalysis, the 4-exo ring closure was preferred over other modes of cyclization.<smiles>[R]C(=O)C([R])([R])C(Br)=C([R])[R]</smiles>

210

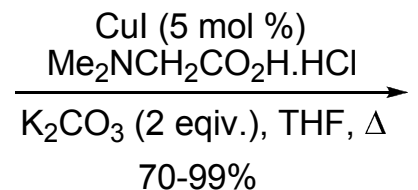

$70-99 \%$

$\mathrm{R}=\mathrm{H}, \mathrm{Me}$

$\mathrm{R}^{1}=\mathrm{R}^{3}=\mathrm{H}, \mathrm{C}_{6} \mathrm{H}_{13}, \mathrm{Me}$

$\mathrm{R}^{2}=\mathrm{H}, \mathrm{Me}, \mathrm{Bn}$

$\mathrm{R}^{4}=\mathrm{Ph}, 4-\mathrm{CO}_{2} \mathrm{MePh}, 4-\mathrm{MePh}, 4-\mathrm{MeOPh}, \mathrm{C}_{12} \mathrm{H}_{25}, \mathrm{C}$-hex, Bn

Scheme 58

\subsection{Cyclization by Formation of $\mathrm{C}_{3}-\mathrm{C}_{4}$ Bond}

Acylation of $\alpha$-amino esters 213, obtained from Tyr(Bz)-OMe and H-Tyr(2,6-ClBz)-OMe 212 via imine formation and reduction of the imine, with $(S)$-2-chloropropanoic acid 214 is reported to afford $N, N$-disubstituted 2-chloropropanamides 215 (Scheme 59). ${ }^{101}$ The products 215 cyclized in the presence of tert-(butylimino)tris(pyrrolidino)phosphorane (BTPP) to afford the 2azetidinones 216. 


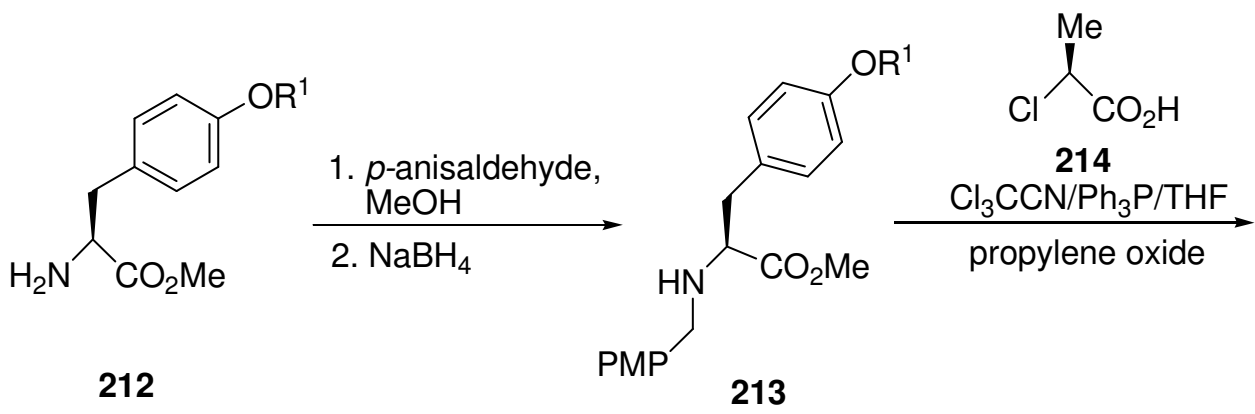<smiles>[CH]C(Cl)C(=O)N(C[R16]#N)C(Cc1ccc(O)cc1)OC(C)=O</smiles>

$\mathrm{R}^{1}=\mathrm{Bn}, 2,4-\mathrm{Cl}_{2} \mathrm{Bn}$
$\mathrm{PMP}=p$-methoxyphenyl

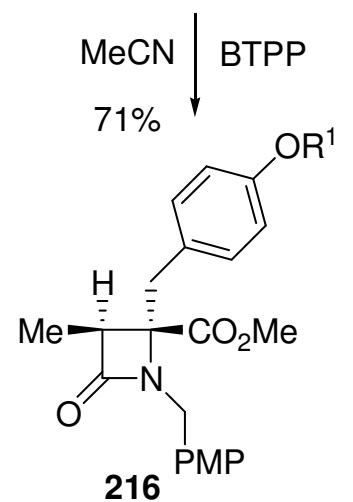

\section{Scheme 59}

The BTPP-induced cyclization of 2-(S)-chloropropionyl amino ester 218, obtained from $(S)$ 2-chloropropanoic acid 214 and amino ester 217, led to the synthesis of 1,3,4-trisubstituted 2azetidinones 219 in enantiopure form (Scheme 60). ${ }^{102}$ A significant amount of a morpholinedione-derivative, the product of $O$-alkylation, was also formed in the reaction. The enantioselectivity has been explained by theoretical calculation of the energies of the transition states leading to either $R, S$ or $S, S$ enantiomer.

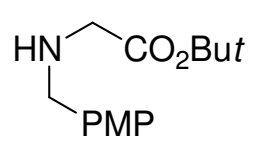

217

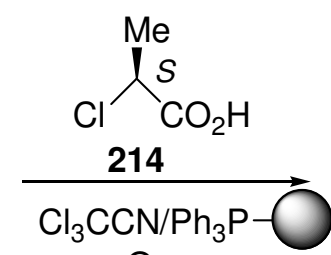

$\triangle$ THF

$\mathrm{PMP}=p$-methoxyphenyl<smiles>CC(=O)OCCN(C[18OH])C(=O)C(C)Cl</smiles>

218

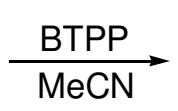



219

\section{Scheme 60}

An excellent electrochemical process is reported for the synthesis of 2-azetidinones employing intramolecular nucleophilic substitution as the key reaction. ${ }^{103}$ Electrochemically generated imidazolium carbene $\mathbf{2 2 1}$ is used to generate the carbanions 222 from the $N, N$ disubstituted $\alpha$-bromoamides 220. Displacement of the bromide by carbanioinc carbon in intermediate 222 affords 2-azetidinones 223 (Scheme 61). 
<smiles>[R]C(Br)C(=O)N([R])C</smiles>

220

$\mathrm{R}^{1}=\mathrm{H}, \mathrm{Me}$

$\mathrm{R}^{2}=4-\mathrm{MeOPh}, \mathrm{MePh}$

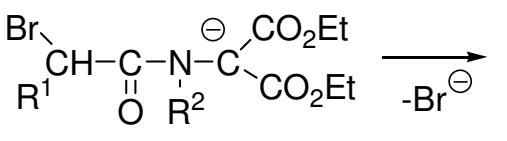

$82-99 \%$<smiles>[R]C1C(=O)N([R2])C1(OCC)OCC</smiles>

223

\section{Scheme 61}

As a first example of a chiral memory effect for a photochemical $\gamma$-hydrogen abstraction, Sakamoto and coworkers have reported the formation of optically active 4-mercapto-2azetidinones 225 by $\mathrm{C}_{3}-\mathrm{C}_{4}$ bond formation via photochemical intramolecular $\gamma$-hydrogen abstraction of thioimides $\mathbf{2 2 4}$. ${ }^{104}$ When optically active monothioimides in toluene solution were irradiated with Pyrex-filtered light from a 500-W high-pressure mercury lamp under argon atmosphere, two diastereomeric 4-mercapto-2-azetidinones were formed together with benzthioanilide $\mathbf{2 2 6}$ in small amounts (Scheme 62).<smiles>[R]C(=S)N(C(=O)[C@H](C)P)C(=O)[C@H](C)S</smiles>

224

$\mathrm{R}=\mathrm{Ph}, 4-\mathrm{MePh}$

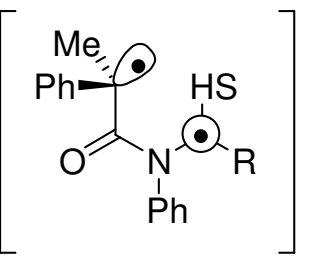

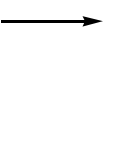
ee $93-96 \%$$$
\begin{aligned}
& (3 \mathrm{R}, 4 \mathrm{~S})-225 \\
& 50-59 \%
\end{aligned}
$$

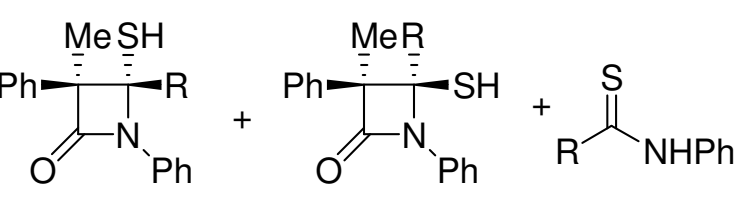

\section{Scheme 62}

A photo-induced reaction of $\alpha$-diazomalonic amide esters is reported in hexane and in nonconventional media such as water or a film with UV light from a mercury vapor highpressure lamp. ${ }^{105}$ The photolytic decomposition of $\alpha$-diazomalonic amide esters 227 in hexane and in water or a film afforded the corresponding $\beta$-lactam-3-carboxylates or 3-phosphonate 228 (Scheme 63) in reasonable yields and in some cases with good diastereoselectivity with no need to use a metallic catalyst. The reaction in water was relatively slow and took $48-72 \mathrm{~h}$ where as it occurred in around $24 \mathrm{~h}$ in hexane. Experimental studies on chiral substrates demonstrated retention of configuration and thus suggesting $\mathrm{C}-\mathrm{H}$ insertion via singlet carbene. 


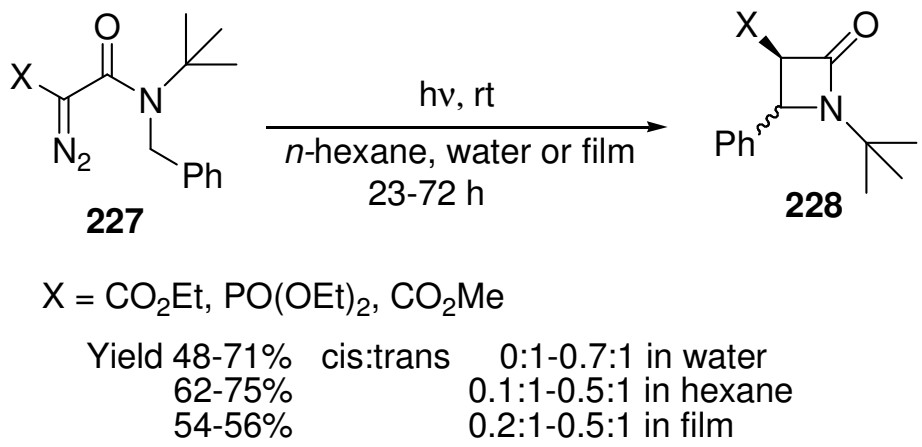

\section{Scheme 63}

\subsection{Multi-Component Reactions}

The design of methodologies involving more than two substrates, usually referred as multicomponent reactions (MCRs), for complex molecular architecture has become an important area of research in organic, medicinal, and combinatorial chemistry. ${ }^{106-108}$ Such strategies reduce the number of reaction steps, thus avoiding too many complicated purification procedures and allowing saving of both solvents and reagents. The Ugi multi-component reactions (MCRs) have been used to construct a variety of 2 -azetidinones starting from $\beta$-amino acids, aldehydes, and isonitriles by Vishwanatha and coworkers. ${ }^{109}$ This group has employed, L-aspartic acid $\alpha$ methyl/peptide ester 229, chiral $\mathrm{N}^{\beta}$-Fmoc amino alkyl isonitriles $\mathbf{2 3 0}$ and aldehydes $\mathbf{2 3 1}$ in the Ugi multi-component reactions to obtain functionalized $\beta$-lactam peptidomimetics 232 (Scheme 64). The reaction is believed to occur through nucleophilic addition of isonitriles on protonated imines 233, followed by cyclization of the resulting intermediates 234 to generate oxazepinones 235 (Scheme 65). An intramolecular $N, O$-acyl migration in oxazepinones 235 leads to the formation of $\beta$-lactam products. ${ }^{109}$

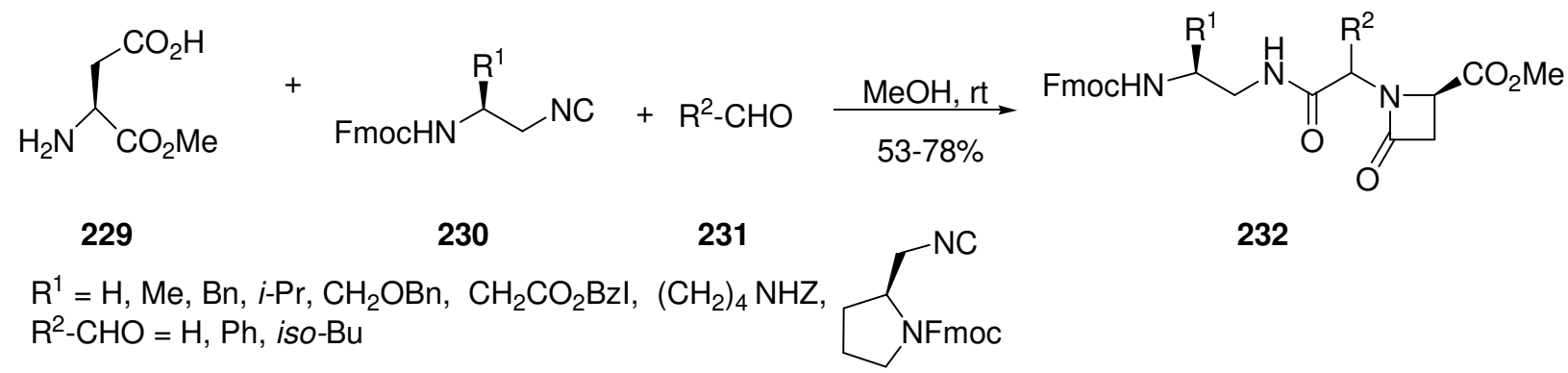

\section{Scheme 64}




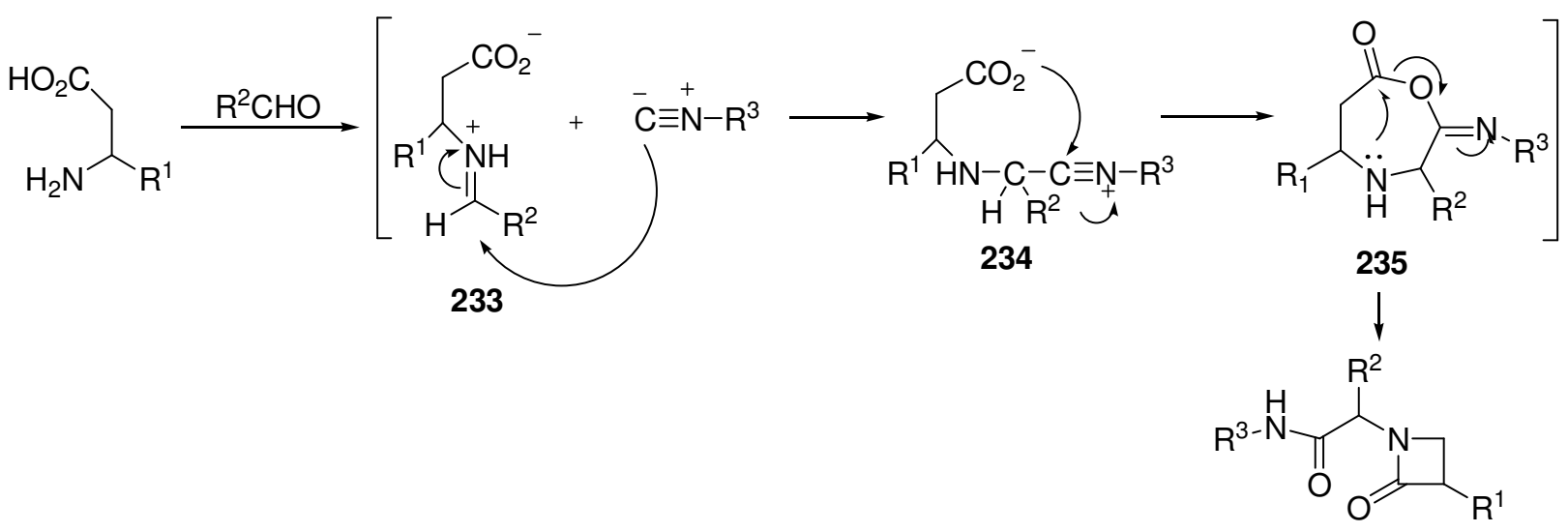

\section{Scheme 65}

Wulff and coworkers have extended their methodology for a multi-component asymmetric synthesis of aziridines from aldehydes, amines, and ethyl diazoacetate to the asymmetric synthesis of 2-azetidinone. ${ }^{89,110}$ The reaction of ethyl diazoacetate 237, butyraldehyde $\mathbf{2 3 8}$ and amine 236 followed by treatment of the resulting aziridine 239 with a base and theVilsmeier reagent led to the formation of 2-azetidinone $\mathbf{2 4 0}$ (Scheme 66).

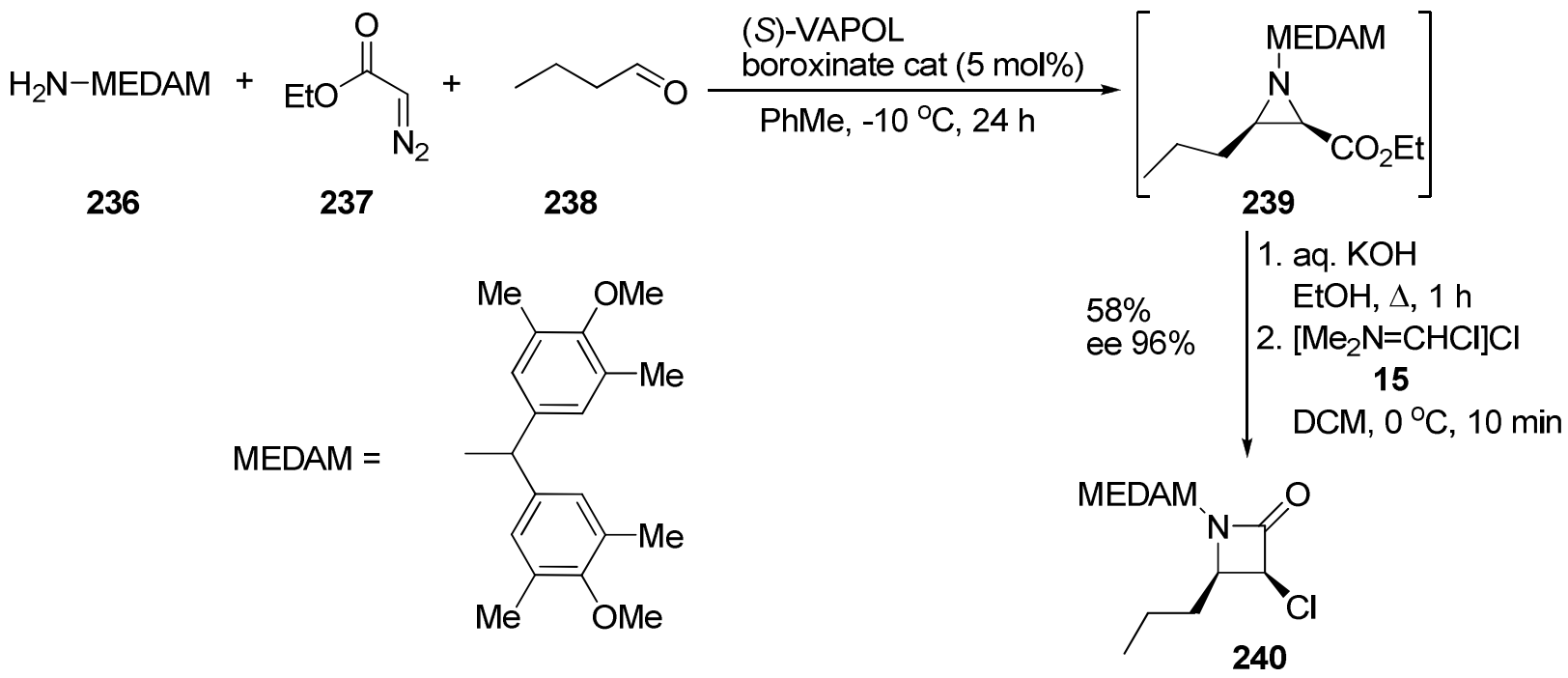

\section{Scheme 66}

\subsection{Other Approaches}

A silylcarbocyclization process by the reaction of $p$-tosylamides 241 with hydrosilane $\mathbf{2 4 2}$ in the presence of a catalytic amount of 1,8-diazabicyclo[5.4.0]undec-7-ene (DBU) leads to the formation of $\alpha$-silylmethylene-2-azetidinones $\mathbf{2 4 3}$ together with a $\beta$-amido aldehyde $\mathbf{2 4 4}$ (Scheme 67). ${ }^{111}$ The structure of the propargyl precursors played a crucial role in the selectivity 
of the reaction, the presence of a bulky propargyl carbon being essential to force the closure of the ring. Moreover the high acidity of the NH-tosyl proton seemed to be fundamental for the $\beta$ lactam formation since the cyclisation process requires the removal of the nitrogen proton by the base DBU. Another report makes use of rhodium nanoparticles derived from mesitylene-solvated $\mathrm{Rh}$ atoms and deposited on inorganic $\left(\mathrm{C}, \gamma-\mathrm{Al}_{2} \mathrm{O}_{3}, \mathrm{Fe}_{2} \mathrm{O}_{3}\right)$ and organic matrices (PBI) (Scheme 68). ${ }^{112}$ The MVS (Metal vapor Synthesis) supported nanoclusters, especially $\mathrm{Rh} / \mathrm{C}$, showed a specific activity much better than the corresponding commercial catalysts $\mathrm{Rh} / \mathrm{C}$ and $\mathrm{Rh} / \gamma-\mathrm{Al}_{2} \mathrm{O}_{3}$ as well as homogenous $\mathrm{Rh}_{4}(\mathrm{CO})_{12}$. The high catalytic activity encountered with $\mathrm{Rh} / \mathrm{C}$ could be ascribed to the easy leaching of metal nanoparticles from carbon into solution. The minor specific activity observed in the cases of metal particles deposited on polar matrices such as PBI and $\mathrm{Fe}_{2} \mathrm{O}_{3}$ could be due to stronger interactions between the rhodium nanoclusters and the support. Therefore MVS Rh/C species represents a source, stable with ageing at room temperature, of highly active metal nanoparticles.



\section{Scheme 67}

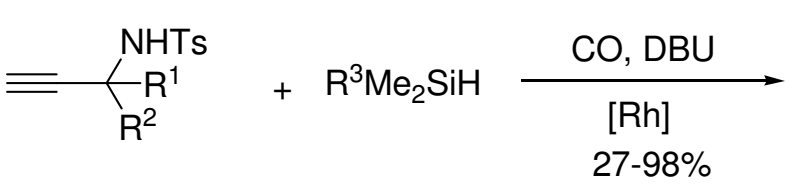

241

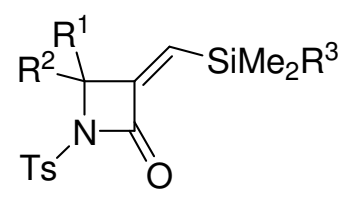

243

$\mathrm{R}^{1}=\mathrm{Et}, \mathrm{Me}, t-\mathrm{Bu} ; \mathrm{R}^{2}=\mathrm{Me} ; \mathrm{R}^{3}=\mathrm{Ph}$

$[\mathrm{Rh}]=\mathrm{Rh} / \mathrm{C}$ (MVS), $\mathrm{Rh} / \mathrm{Fe}_{2} \mathrm{O}_{3}$ (MVS), $\mathrm{Rh} / \gamma-\mathrm{Al}_{2} \mathrm{O}_{3}$ (MVS), Rh/PBI (MVS), $\mathrm{Rh}_{4} \mathrm{CO}_{4}$

\section{Scheme 68}

An approach involving thiazolidine ring opening of penam nucleus is reported for synthesis of $\mathrm{N}$-isothiazolidinone substituted 2-azetidinone from penam amides 246, which in turn was derived by amidation of 6-phthalimido-penicillanic acid $\mathbf{2 4 5}$. The reaction involved treatment of 
phthalimido-penam amides with sulfuryl chloride to afford a mixture of cis $\mathbf{2 4 7}$ and trans $\mathbf{2 4 8}$ diastereoisomers of monocyclic 2-azetidinones (Scheme 69). ${ }^{113}$

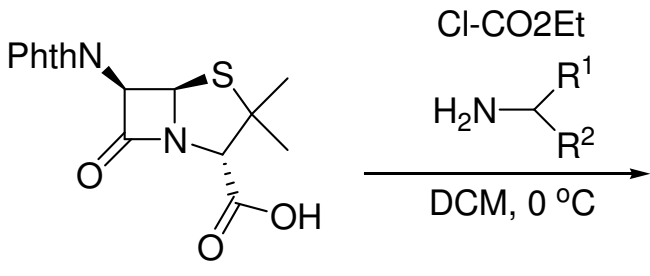

245

$\mathrm{R}_{1}=\mathrm{Ph}, \mathrm{Me}, \mathrm{H}$

$\mathrm{R}_{2}=\mathrm{CO}_{2} \mathrm{Bn}, \mathrm{Bn}, \mathrm{Me}$

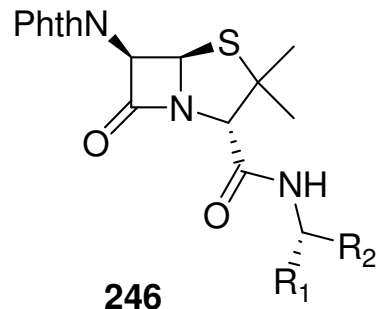

246

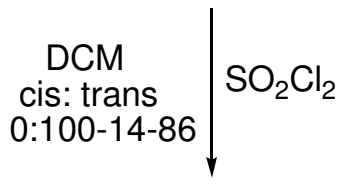

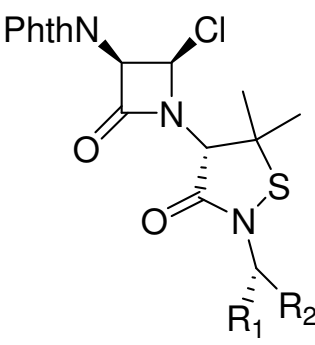

247

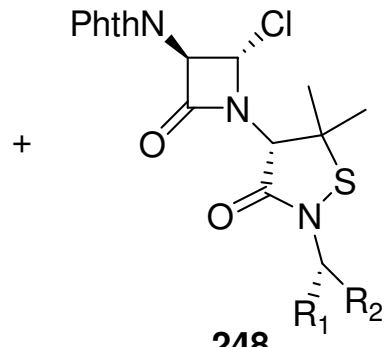

248

\section{Scheme 69}

\section{Concluding Remarks}

The research on methodologies to synthesize monocyclic 2-azetidinone ring has advanced remarkably during the last five years. Several new heteroatom-substituted ketenes have been employed efficiently in the Staudinger reaction furnishing 2-azetidinones containing heteroatoms such as nitrogen, sulfur, fluorine, and selenium at C-3 position. Several novel azomethines have been employed too. These include $N$-nosyl imines, $N$-sulfenyl imines, anthraquinone imines, $N$ tosyl-1-chloro-2,2,2-trifluoroethylamine, and also the Wittig reagent. Several new efficient acid activators such as diethyl chlorophosphate, cyanuric chloride-DMF complex, thiocarbonyldiimidazole, cyanuric fluoride, and phosphonitrilic chloride have been invented. Application of heterocyclic carbenes in the Staudinger reactions has led to a highly enantioselective synthesis of 2-azetidinones. Besides the ester-enolate cycloadditions, alkynenitrone cycloadditions have emerged as a powerful method for enantioselective synthesis of monocyclic 2-azetidinones. Diverse types of new $\beta$-amino esters have been synthesized and cyclized to 2-azetidinones. Photochemical and catalytic decompositions of appropriate diazocarbonyls followed by cyclization also constitute appealing methodology for synthesizing monocyclic 2-azetidinones. The Ugi multi-component reactions (MCRs) have been used to 
construct a variety of 2-azetidinones starting from $\beta$-amino acids, aldehydes, and isonitriles. Another multicomponent reaction of ethyl diazoacetate, amine and aldehyde has led to a highly enantioselective synthesis of 2-azetidinones through aziridine ring-expansion. This significant development would definitely continue to encourage further research in this area.

\section{Abbreviations}

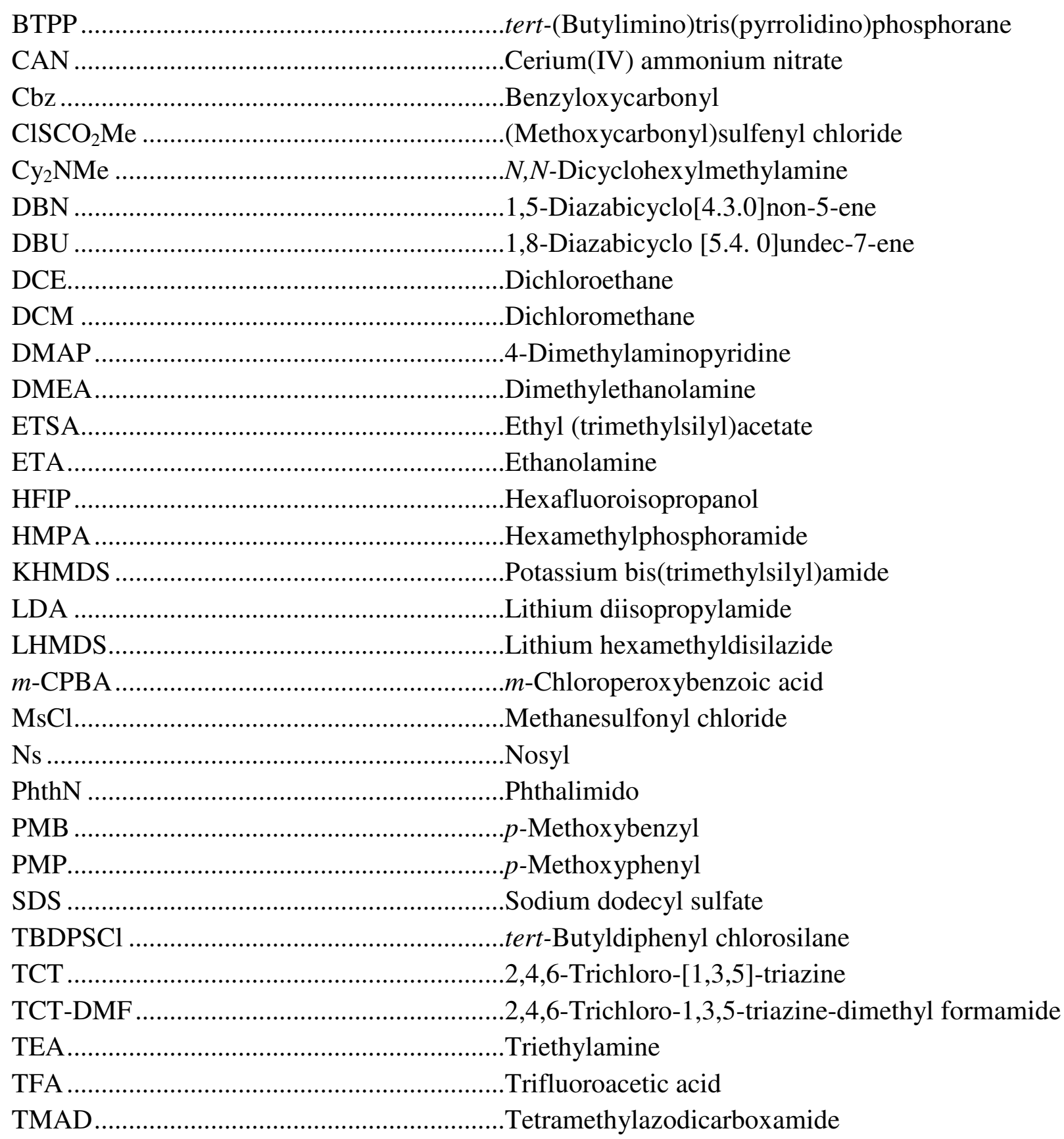


TMG Trimethylglycine

TMS Trimethylsilyl

$\mathrm{TMSCHN}_{2}$ Trimethylsilyldiazomethane

TMSCl .Chlorotrimethylsilane

Ts. Tosyl

VAPOL -2,2'-Diphenyl-4-(biphenanthrol)

\section{Acknowledgements}

Authors are thankful to the Chemistry Department, University of Botswana, Gaborone, Botswana, for providing facilities.

\section{References}

1. Aranda, M. T.; Perez-Faginas, P.; Gonzalez-Muniz, R. Curr. Org. Synth. 2009, 6, 325. http://dx.doi.org/10.2174/157017909788921899

2. Hwu, J. R.; Ethiraj, K. S.; Hakimelahi, G. H. Min-Rev. Med. Chem. 2003, 3, 205.

3. Singh, G. S. Mini-Rev. Med. Chem. 2004, 4, 69. http://dx.doi.org/10.2174/1389557043487501

4. Singh, G. S. Min-Rev. Med. Chem. 2004, 4, 93.

5. Mehta, P. D.; Sengar, N. P. S.; Pathak, A. K. Eur. J. Med. Chem. 2010, 45, 5541. http://dx.doi.org/10.1016/j.ejmech.2010.09.035

6. Mukerjee, A. K.; Singh, A. K. Synthesis 1975, 547. http://dx.doi.org/10.1055/s-1975-23842

7. Alcaide, B.; Almendros, P. Curr. Med. Chem. 2004, 11, 1921. http://dx.doi.org/10.2174/0929867043364856

8. Deshmukh, A. R. A. S; Bhawal, B. M.; Krishnaswamy, D.; Govande, V. V.; Shinkre, B. A.; Jayanthi, A. Curr. Med. Chem. 2004, 11, 1889. http://dx.doi.org/10.2174/0929867043364874

9. Van Brabandt, W.; Dejaegher, Y.; De Kimpe, N. Pure Appl. Chem. 2005, 77, 2061. http://dx.doi.org/10.1351/pac200577122061

10. Alcaide, B.; Almendros, P.; Aragoncillo, C. Chem. Rev. 2007, 107, 4437. http://dx.doi.org/10.1021/cr0307300

11. D'hooghe, M.; Dekeukeleire, S.; Leemans, E.; De Kimpe, N. Pure Appl. Chem. 2010, 82, 1749.

12. Singh, G. S. Mod. Chem. Appl. 2013, 1, e108. 
http://dx.doi.org/10.4172/mca.1000.e108

13. Alcaide, B.; Almendros, P. Chem. Record 2011, 11, 311.

http://dx.doi.org/10.1002/tcr.201100011

14. Mukerjee, A. K.; Singh, A. K. Tetrahedron 1978, 34, 1731.

http://dx.doi.org/10.1016/0040-4020(78)80209-9

15. Singh, G. S. Tetrahedron 2003, 59, 7631.

http://dx.doi.org/10.1016/S0040-4020(03)01099-8

16. Singh, G. S.; D’hooghe, M.; De Kimpe, N. In Azetidines, Azetines, and Azetes in Comprehensive Heterocyclic Chemistry-III; eds. Katritzky, A. R.; Ramsden, C. A.; Scriven, E.; Taylor, R.; Elsevier: UK, 2008; vol. 2, p 1. http://dx.doi.org/10.1016/B978-008044992-0.00201-7

17. Singh, G. S.; D’hooghe, M.; De Kimpe, N. Tetrahedron 2011, 67, 1989. http://dx.doi.org/10.1016/j.tet.2011.01.013

18. Kamath, A.; Ojima, I. Tetrahedron 2012, 68, 10640. http://dx.doi.org/10.1016/j.tet.2012.07.090

19. Alcaide, B.; Almendros, P.; Aragoncillo, C. Curr. Opin. Drug Disc. Dev. 2010, 13, 685.

20. Staudinger, H. Liebigs Annal. chem. 1907, 356, 51.

21. Xu, J. Arkivoc 2009, ix, 21.

22. Tuba, R. Org. Biomol. Chem. 2013, 11, 5976. http://dx.doi.org/10.1039/c3ob41048j

23. Singh, G. S. Curr. Org. Synth. 2005, 2, 377. http://dx.doi.org/10.2174/1570179054368536

24. Bose, A. K.; Banik, B. K.; Manhas, M. S. Tetrahedron Lett.1995, 36, 213. http://dx.doi.org/10.1016/0040-4039(94)02225-Z

25. Laborde, M. A.; Mata, E. G. Mini-Rev. Med. Chem. 2006, 6, 109. http://dx.doi.org/10.2174/138955706775197794

26. Banik, B. K.; Banik, I.; Becker, F. F. Eur. J.Med. Chem. 2010, 45, 846. http://dx.doi.org/10.1016/j.ejmech.2009.11.024

27. Marques-Lopez, E.; Martin-Zamora, E.; Diez, E.; Fernandez, R.; Lassaletta, J. M. Eur. J. Org. Chem. 2008, 17, 2960.

http://dx.doi.org/10.1002/ejoc.200800194

28. Islami, M. R.; Allen, A. D.; Vukovic, S.; Tidwell, T. T. Org. Lett. 2011, 13, 494. http://dx.doi.org/10.1021/ol102837n

29. Zarei, M.; Mohamadzadeh, M. Tetrahedron 2011, 67, 5832. http://dx.doi.org/10.1016/j.tet.2011.05.043

30. Bari, S. S.; Bhalla, A.; Nagpal, Y.; Mehta, S. K.; Bhasin, K. K. J. Organometall. Chem. 2010, 695, 1979. http://dx.doi.org/10.1016/j.jorganchem.2010.05.005

31. Bhalla, A.;Venugopalan, P.; Bhasin, K. K.; Bari, S. S. Tetrahedron 2007, 63, 3195. http://dx.doi.org/10.1016/j.tet.2007.02.001 
32. Jarrahpour, A.; Ebrahimi, E.; Khalifeh, R.; Sharghi, H.; Sahraei, M.; Sinou, V.; Latour, C.; Brunel, J. M. Tetrahedron 2012, 68, 4740.

http://dx.doi.org/10.1016/j.tet.2012.04.011

33. Wang, Z.; Chen, N.; Xu, J. Tetrahedron 2011, 67, 9690.

http://dx.doi.org/10.1016/j.tet.2011.10.044

34. Tato, F.; Reboul, V.; Metzner, P. J. Org. Chem. 2008, 73, 7837. http://dx.doi.org/10.1021/jo8014193

35. Venkateshwarlu, J.; Ramakanth, P.; Meshram, J. S.; Chopde, H. N.; Malladi, L. J. Heterocycl. Chem. 2013, 50, E160. http://dx.doi.org/10.1002/jhet.1108

36. Cariou, C. C. A.; Clarkson, G. J.; Shipman, M. J. Org. Chem. 2008, 3, 9762. http://dx.doi.org/10.1021/jo801664g

37. D'hooghe, M.; Brabandt, W. V.; Dekeukeleire, S.; Dejaegher,Y.; De Kimpe, N. Chem. Eur. J. 2008, 6336. http://dx.doi.org/10.1002/chem.200800845

38. Coantic, S.; Mouysset, D.; Mignani, S.; Tabart, M.; Stella, L. Tetrahedron 2007, 63, 3205. http://dx.doi.org/10.1016/j.tet.2007.01.051

39. Yang, Y-Y.; Shou, W-G.; Hong, D.; Wang, Y-G. J. Org. Chem. 2008, 73, 3574. http://dx.doi.org/10.1021/jo702733h

40. Petrik, V.; Roschenthaler, G. V.; Cahard, D. Tetrahedron 2011, 67, 3254. http://dx.doi.org/10.1016/j.tet.2011.03.001

41. Shaikh, A. L.; Kale, A.S.; Shaikh, M. A.; Puranik, V. G.; Deshmukh, A. R. A. S. Tetrahedron 2007, 63, 3380.

http://dx.doi.org/10.1016/j.tet.2007.02.022

42. Zarei, M. J. Chem. Res. 2012, 118.

43. Zarei, M.; Jarrahpour, A. Synlett 2011, 2572.

44. Zarei, M.; Karimi-Jaberi, Z.; Movahedi, A. Synth. Commun. 2013, 43, 728. http://dx.doi.org/10.1080/00397911.2011.607935

45. Jarrahpour, A.; Zarei, M. Tetrahedron Lett. 2009, 50, 1568. http://dx.doi.org/10.1016/j.tetlet.2009.01.092

46. Zarei, M. J. Chem. Res. 2013, 25.

47. Zarei, M. Tetrahedron 2013, 69, 6620. http://dx.doi.org/10.1016/j.tet.2013.05.121

48. Bandopadhyay, D.; Cruz, J.; Banik, B. K. Tetrahedron 2012, 68, 10686. http://dx.doi.org/10.1016/j.tet.2012.06.009

49. Banik, B. K.; Banik, I.; Becker, F. F. Bioorg. Med. Chem. 2005, 13, 3611. http://dx.doi.org/10.1016/j.bmc.2005.03.044

50. Delpiccolo, C. M. L.; Testero, S. A.; Leyes, F. N.; Boggian, D. B.; Camacho, C. M.; Mata, E. G. Tetrahedron 2012, 68, 10780. http://dx.doi.org/10.1016/j.tet.2012.01.072 
51. Zhang, Z.; Liu,Y.; Ling, L.; Li, Y.; Dong, Y.; Gong, M.; Zhao, X.; Zhang, Y.; Wang, J. J. Am. Chem. Soc. 2011, 133, 4330.

http://dx.doi.org/10.1021/ja107351d

52. Duguet, N.; Donaldson, A.; Leckie, S. M.; Kallstrom, E. A.; Campbell, C. D.; Shapland, P.; Brown, T. B.; Slawin, A. M. Z.; Smith, A. D. Tetrahedron: Asymmetry 2010, 21, 601. http://dx.doi.org/10.1016/j.tetasy.2010.03.002

53. Duguet, N.; Donaldson, A.; Leckie, S. M.; Douglas, J.; Shapland, P.; Brown, T. B.; Slawin, A. M. Z.; Smith, A. D.; Churchil, G. Tetrahedron: Asymmetry 2010, 21, 582. http://dx.doi.org/10.1016/j.tetasy.2010.03.001

54. Duguet, N.; Campbell, C. D.; Slawin, A. M. Z.; Smith, A. D. Org. Biomol. Chem. 2008, 6, 1108.

http://dx.doi.org/10.1039/b800857b

55. Zhang, Y-R.; He, L.; Wu, X.; Shao, P-L.; Ye, S. Org. Lett. 2008, 10, 277. http://dx.doi.org/10.1021/o1702759b

56. Abraham, C. J.; Paull, D. H.; Dogo-Isonagie, C.; Lectka, T. Synlett 2009, 1651.

57. D'hooghe, M.; Dejaegher, Y.; De Kimpe, N. Tetrahedron 2008, 64, 4575. http://dx.doi.org/10.1016/j.tet.2008.03.006

58. Singh, P.; Sachdeva, S.; Raj, R.; Kumar, V.; Mahajan, M. P.; Nasser, S.; Vivas, L.; Gut, J.; Rosenthal, P. J.; Feng, T.-S.; Chibale, K. Bioorg. Med. Chem. Lett. 2011, 21, 4561. http://dx.doi.org/10.1016/j.bmcl.2011.05.119

59. Singh, G. S.; Pandeya, S. N. J. Chem. Engg. Data 1987, 32, 278. http://dx.doi.org/10.1021/je00048a037

60. Qi, H.; Yang, Z.; Xu, J. Synthesis 2011, 723.

61. Kirmse, W. Eur. J. Org. Chem. 2002, 2193. http://dx.doi.org/10.1002/1099-0690(200207)2002:14<2193::AID-EJOC2193>3.0.CO;2-D

62. Singh, G. S.; Al-Kahraman, Y. M. S. A.; Mpadi, D.; Yasinzai, M. Bioorg. Med. Chem. Lett. 2012, 22, 5704.

http://dx.doi.org/10.1016/j.bmcl.2012.06.081

63. Singh, G. S.; Al-Kahraman, Y. M. S. A.; Mpadi, D.; Yasinzai, M. J. Heterocycl. Chem. 2013, in press.

64. Singh, G. S.; Mbukwa, E.; Pheko, T. Arkivoc 2007, ix, 80.

65. Boyer, N.; Gloanec, P.; Nanteuil, G. D.; Jubault, P.; Quirion, J-C. Tetrahedron 2007, 63, 12352.

http://dx.doi.org/10.1016/j.tet.2007.09.058

66. Tarui, A.; Ozaki, D.; Nakajima, N.; Yokota, Y.; Sokeirik, Y. S.; Sato, K.; Omote, M.; Kumadaki, I.; Ando, A. Tetrahedron Lett. 2008, 49, 3839.

http://dx.doi.org/10.1016/j.tetlet.2008.04.101

67. Soengas, R. G.; Segade, Y.; Jimenez, C.; Rodriguez, J. Tetrahedron 2011, 67, 2617. http://dx.doi.org/10.1016/j.tet.2011.02.006 
68. Tarui, A.; Kawashima, N.; Sato, K.; Omote, M.; Miwa, Y.; Minami, H.; Ando, A. Tetrahedron Lett. 2010, 51, 2000. http://dx.doi.org/10.1016/j.tetlet.2010.02.023

69. Gembus, V.; Poisson, T.; Oudeyer, S.; Marsais, F.; Levacher, V. Synlett 2009, 2437.

70. Michel, K.; Frohlich, R.; Wurthwein, E-U. Eur. J. Org. Chem. 2009, 5653. http://dx.doi.org/10.1002/ejoc.200900864

71. Boyer, N.; Gloanec, P.; Nanteuil, G. D.; Jubault, P.; Quirion, J. C. Eur. J. Org. Chem. 2008 4277.

http://dx.doi.org/10.1002/ejoc.200800363

72. Michalak, M.; Stodulski, M.; Stecko, S.; Mames, A.; Panfil, I.; Soluch, M.; Furman, B.; Chmielewski, M. J. Org. Chem. 2011, 76, 6931.

http://dx.doi.org/10.1021/jo2010846

73. Wu, G.; Wong, Y.; Chen, X.; Ding, Z. J. Org. Chem. 1999, 64, 3714. http://dx.doi.org/10.1021/jo990428k

74. Zhang, X.; Hsung, R. P.; Li, H.; Zhang, Y.; Johnson, W. L.; Figueroa, R. Org. Lett. 2008, $10,3477$.

http://dx.doi.org/10.1021/ol801257j

75. McKay, C. S.; Kennedy, D. C.; Pezacki, J. P. Tetrahedron Lett. 2009, 50, 1893. http://dx.doi.org/10.1016/j.tetlet.2009.02.035

76. Michalak, M.; Stodulski, M.; Stecko, S.; Woznica, M.; Staszewska-Krajewska, O.; Kalicki, P.; Furman, B.; Frelek, J.; Chmielewski, M. Tetrahedron 2012, 68, 10806. http://dx.doi.org/10.1016/j.tet.2011.11.007

77. Coyne, A. G.; Muller-Bunz, H.; Guiry, P. J. Tetrahedron: Asymmetry 2007, 18, 199. http://dx.doi.org/10.1016/j.tetasy.2007.01.006

78. Chen, J-H.; Liao, S-H.; Sun, X-L.; Shen, Q.; Tang, Y. Tetrahedron 2012, 68, 5042. http://dx.doi.org/10.1016/j.tet.2012.04.049

79. Saito, T.; Kikuchi, T.; Tanabe, H.; Yahiro, J.; Otani, T. Tetrahedron Lett. 2009, 50, 4969. http://dx.doi.org/10.1016/j.tetlet.2009.06.050

80. Baeza, B.; Casarrubios, L.; Sierra, M. A. Chem. Eur. J. 2013, 19, 11536. http://dx.doi.org/10.1002/chem.201301114

81. Lee, S. H. Bull. Korean Chem. Soc. 2013, 34, 121. http://dx.doi.org/10.5012/bkcs.2013.34.1.121

82. Troisi, L.; Ronzini, L.; Granito, C.; Vitis, L. D.; Pindinelli, E. Tetrahedron 2006, 62, 1564. http://dx.doi.org/10.1016/j.tet.2005.11.007

83. Torii, S.; Okumoto, H.; Sadakane, M.; Hai, A.;Tanaka, H. Tetrahedron Lett. 1993, 34, 6553.

http://dx.doi.org/10.1016/0040-4039(93)88102-O

84. Tanaka, H.; Hai, A.; Sadakane, M.; Okumoto, H.; Torii, S. J. Org. Chem. 1994, 59, 3040. http://dx.doi.org/10.1021/jo00090a023

85. Troisi, L.; Granito, C.; Pindinelli, E. Tetrahedron 2008, 64, 11632. 
http://dx.doi.org/10.1016/j.tet.2008.10.027

86. Xie, P.; Qian, B.; Huang, H.; Xia, C. Tetrahedron Lett. 2012, 53, 1613.

http://dx.doi.org/10.1016/j.tetlet.2012.01.073

87. Troisi, L.; Pindinelli, E.; Strusi, V.; Trinchera, P. Tetrahedron: Asymmetry 2009, 20, 368. http://dx.doi.org/10.1016/j.tetasy.2009.01.012

88. Fontana, F.; Tron, G. C.; Barbero, N.; Ferrini, S.; Thomas, S. P.; Aggarwal, V. K. Chem. Commun. 2010, 267.

http://dx.doi.org/10.1039/b920564k

89. Huang, L.; Zhao, W.; Staples, R. J.; Wulff, W. D. Chem. Sci. 2013, 4, 622. http://dx.doi.org/10.1039/c2sc21240d

90. Guerrini, A.; Varchi, G.; Samori, C.; Daniele, R.; Arturo, B. Tetrahedron Lett. 2007, 48, 5081.

http://dx.doi.org/10.1016/j.tetlet.2007.05.087

91. Dema, H. K.; Foubelo, F.; Yus, M. Helvetica Chim. Acta 2012, 95, 1790. http://dx.doi.org/10.1002/hlca.201200303

92. Kashikura, W.; Mori, K.; Akiyama, T. Org. Lett. 2011, 13, 1860. http://dx.doi.org/10.1021/ol200374m

93. Gianelli, C.; Sambri, L.; Carlone, A.; Bartoli, G.; Melchiorre, P. Angew. Chem. Int. Ed. 2008, 47, 8700 . http://dx.doi.org/10.1002/anie.200803819

94. Jakowiecki, J.; Loska, R.; Makosza, M. J. Org. Chem. 2008, 73, 5436. http://dx.doi.org/10.1021/jo800721w

95. Hachiya, I.; Yoshitomi, T.; Yamaguchi, Y.; Shimizu, M. Org. Lett. 2009,11, 3266. http://dx.doi.org/10.1021/o1901192y

96. Vaske, Y. S. M.; Mahoney, M. E.; Konopelski, J. P.; Rogow, D. L.; McDonald, W. J. J. Am. Chem. Soc. 2010, 132, 11379.

http://dx.doi.org/10.1021/ja1050023

97. Gerstenberger, B. S.; Lin, J. Z.; Mimieux, Y. S.; Brown, L. E.; Oliver, A. G.; Konopelski, J. P. Org. Lett. 2008, 10, 369. http://dx.doi.org/10.1021/ol7025922

98. Lu, X.; Long, T. E. Tetrahedron Lett. 2011, 52, 5051. http://dx.doi.org/10.1016/j.tetlet.2011.07.085

99. Yang, Y.; Xiang, D.; Zhao, X.; Liang, Y.; Huang, J.; Dong, D. Tetrahedron 2008, 64, 4959.

http://dx.doi.org/10.1016/j.tet.2008.03.093

100. Zhao, Q.; Li, C. Org. Lett. 2008, 10, 4037. http://dx.doi.org/10.1021/o1801545a

101. Perez-Faginas, P.; Aranda, M. T.; Garcia-Lopez, M. T.; Francesch, A.; Cuevas, C.; Gonzalez-Muniz, R. Eur. J. Med. Chem. 2011, 46, 5108.

http://dx.doi.org/10.1016/j.ejmech.2011.08.025 
102. Perez-Faginas, P.; Alkorta, I.; Garcia-Lopez, M. T.; Gonzalez-Muniz, R. Tetrahedron Lett. 2008, 49, 215.

http://dx.doi.org/10.1016/j.tetlet.2007.11.099

103. Sotgiu, G.; Chiarotto, I.; Feroci, M.; Orsini, M.; Rossi, L.; Inesi, A. Electrochim. Acta 2008, 53, 7852 .

http://dx.doi.org/10.1016/j.electacta.2008.05.054

104. Sakamoto, M.; Kawanishi, H.; Mino, T.; Fujita, T. Chem. Commun. 2008, 2132.

http://dx.doi.org/10.1039/b801524d

105. Candeias, N. R.; Gois, P. M. P.; Veiros, L. F.; Afonso, C. A. M. J. Org. Chem. 2008, 73, 5926.

http://dx.doi.org/10.1021/jo800980c

106. Domling, A.; Wang, W.; Wang, K. Chem. Rev. 2012, 112, 3083.

http://dx.doi.org/10.1021/cr100233r

107. Liu, H.; Dou, G.; Shi, D. J. Comb. Chem. 2010, 12, 633.

http://dx.doi.org/10.1021/cc100035q

108. Litvinov, Y. M.; Shestopalov, A. A.; Rodinovskaya, L. A.; Shestopaqlov, A. M. J. Comb. Chem. 2009, 11, 914.

http://dx.doi.org/10.1021/cc900076j

109. Vishwanatha, T. M.; Narendra, N.; Sureshbabu, V. V. Tetrahedron Lett. 2011, 52, 5620. http://dx.doi.org/10.1016/j.tetlet.2011.08.090

110. Gupta, A. K.; Mukherjee, M.; Wulff, W. D. Org. Lett. 2011, 13, 5866.

http://dx.doi.org/10.1021/ol202472z

111. Aronica, L. A.; Valentini, G.; Caporusso, A. M.; Salvadori, P. Tetrahedron 2007, 63, 6843. http://dx.doi.org/10.1016/j.tet.2007.04.064

112. Aronica, L. A.; Caporusso, A. M.; Evangelisti, C.; Botavina, M.; Alberto, G.; Martra, G. J. Organometall. Chem. 2012, 700, 20.

http://dx.doi.org/10.1016/j.jorganchem.2011.11.008

113. Ceric, H.; Sindler-Kulyk, M.; Kovacevic, M.; Peric, M.; Zivkovic, A. Bioorg. Med. Chem. 2010, $18,3053$.

http://dx.doi.org/10.1016/j.bmc.2010.03.045 


\section{Authors Biographies}

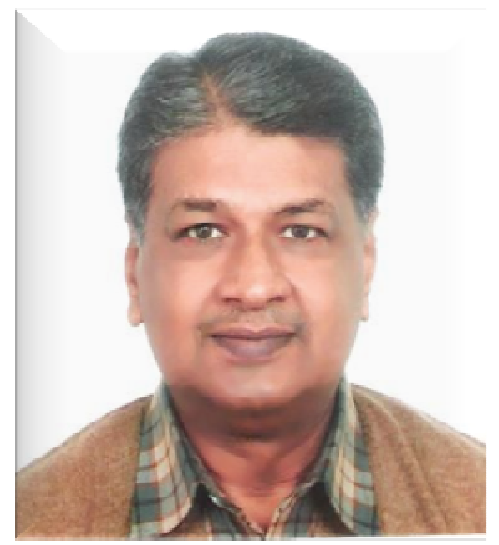

Girija S. Singh was born in Sasaram (Bihar), India. He received his B. Sc. and M. Sc. degrees from the U. P. College (then Gorakhpur University), Varanasi, India, in 1977 and 1979, respectively. He received his $\mathrm{Ph}$. D. degree from the Banaras Hindu University (BHU), India, completing his doctoral thesis on the reactions of diazoalkanes and diazoketones with imines, amines and hydrazones in October, 1984. Since then he has occupied teaching and research positions in various universities such as Banaras Hindu University, India (JRF, SRF, PDF, Research Associate, Pool-Officer, Reader), Osaka University, Japan (PDF), University of Zambia (Lecturer), and University of Botswana (Lecturer, Senior Lecturer, Associate Professor). $\mathrm{He}$ is currently working as Professor of Chemistry at the University of Botswana. He has authored eighty five publications in books and in peer-reviewed journals. He is member of the American Chemical Society, Chemical Research Society of India, and Indian Chemical Society. $\mathrm{He}$ is on the editorial board of over half a dozen chemistry journals. His research interests include the study of synthesis and reactivity of biologically important heterocycles, reactions of carbenoids, metal-catalyzed oxidations and organic chemistry education.

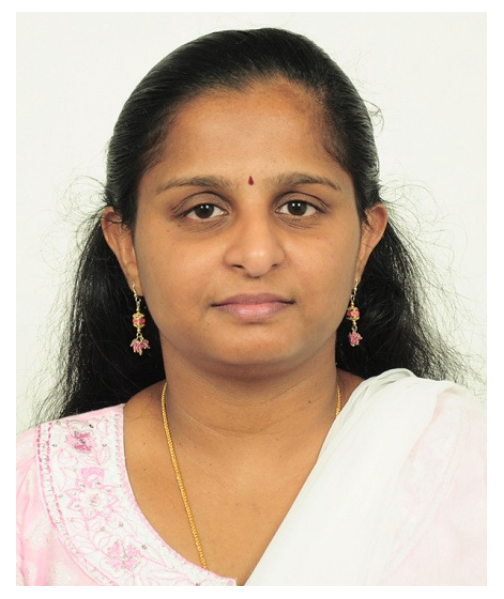

Siji Sudheesh was born in Thrissur (Kerala), India. She obtained her B. Sc. and M. Sc. degrees from Calicut University, India, in 2002 and 2006, respectively. After working briefly as a 
demonstrator in Chemistry Department of the University of Botswana, she joined the Ph. D. program of the department in 2011. Her research focuses on the interaction, hysteresis and reactions of mixed Langmuir monolayers over air/aqueous interface. She has so far published three papers. 